\title{
Systematic change in relative stabilities of REE-humic complexes at various metal loading levels
}

\author{
YUHEI YAMAMOTO, ${ }^{1 *}$ YOSHIO TAKAHASHI ${ }^{1,2}$ and HIROSHI SHIMIZU ${ }^{1,2}$ \\ ${ }^{1}$ Department of Earth and Planetary Systems Science, Graduate School of Science, Hiroshima University, \\ Higashi-Hiroshima, Hiroshima 739-8526, Japan \\ ${ }^{2}$ Laboratory for Multiple Isotope Research for Astro- and Geochemical Evolution (MIRAGE), Hiroshima University, \\ Higashi-Hiroshima, Hiroshima 739-8526, Japan
}

(Received October 30, 2008; Accepted June 2, 2009)

\begin{abstract}
Complexation of rare earth elements (REEs) with humic substances (HSs) at various REE loading levels was studied by solvent extraction and equilibrium dialysis methods coupled with inductively coupled plasma-mass spectrometry (ICPMS). Apparent stability constants $\left(\beta_{\mathrm{M}-\mathrm{HS}}\right)$ of REE ions with standard Suwannee River humic acid (SRHA) were determined simultaneously for all REEs except for Pm. $\beta_{\mathrm{M}-\mathrm{HS}}$ depends on the REE loading level to HSs, where $\beta_{\mathrm{M}-\mathrm{HS}}$ decreases with an increase in the REE loading level at a lower REE loading region, whereas $\beta_{\mathrm{M}-\mathrm{HS}}$ is almost constant beyond a certain REE loading level. The variation in $\beta_{\mathrm{M}-\mathrm{HS}}$ with the REE loading level suggests the existence of several types of binding sites of REEs in HSs. Next, $\beta_{\mathrm{M}-\mathrm{HS}}$ was converted into $K_{\mathrm{MA}}$ (which is the REE-HS interaction parameter for Tipping's "Humic Ion-Binding Model VI") to be compared with the data by previous studies on REE-HS complexation at various REE loading levels in terms of relative differences among REEs (i.e., REE pattern). In the case of solvent extraction, the REE pattern of $\log K_{\mathrm{MA}}$ changes with variation in the REE loading level; a peak around Sm and Eu was observed in the REE pattern of $\log K_{\mathrm{MA}}$ at a higher REE loading region, whereas $\log K_{\mathrm{MA}}$ increases with an increase in the atomic number of REEs at a lower REE loading region. On the other hand, such variation in the REE pattern of $\log K_{\mathrm{MA}}$ was not observed in the results of equilibrium dialysis. This difference in the REE pattern of $\log K_{\mathrm{MA}}$ can be explained by the total metal loading level, including the contributions of $\mathrm{Fe}^{3+}$ and $\mathrm{Al}^{3+}$ originally contained in $\mathrm{HS}$.

The main binding sites of REEs in HSs were determined by comparing the REE pattern of $\log K_{\mathrm{MA}}$ experimentally obtained for HSs with those estimated based on the linear free-energy relationship (LFER) for carboxylates. Similarity of the REE pattern suggested that simple carboxylates are the main binding sites of REEs at a higher metal loading region, whereas chelating sites play a key role at a lower metal loading region. Our results show that relative stabilities of HS complexes among various REEs can change as a function of the metal loading level.
\end{abstract}

Keywords: humic substances, stability constants, metal loading, REE pattern, binding site

\section{INTRODUCTION}

Relative abundances of rare earth elements (REEs), known as REE patterns in natural terrestrial waters, have been studied widely to ascertain the source material, path of transport, and carrier controlling behavior of REEs in the aquatic system (Henderson, 1984; Bertram and Elderfield, 1993; Bau and Dulski, 1996; Gaillardet et al., 1997; Johannesson et al., 1999). In the system, REE fractionation occurs during the reactions of dissolved REE species with particulate matter in natural terrestrial water reflecting similar but slightly different chemical prop-

*Corresponding author (e-mail: yamamoto.yuhei@jaea.go.jp)

* Present address: Tono Geoscientific Research Unit, Geological Isolation Research and Development Directorate, Japan Atomic Energy Agency (JAEA), Mizunami, Gifu 509-6132, Japan.

Copyright $@ 2010$ by The Geochemical Society of Japan. erties among REEs (Tanizaki et al., 1992; Ingri et al., 2000; Nozaki et al., 2000; Pokrovsky and Schott, 2002; Nelson et al., 2003; Tang and Johannesson, 2005). To understand this fractionation, it is essential to know the chemical state of REEs in water and on particulate matter, which controls systematic fractionation of REEs during adsorption-desorption reactions. However, the chemical states in these phases are not determined fully due to difficulties in direct measurement of REE species in natural terrestrial water with their low concentrations (Gaillardet et al., 2003).

On the other hand, the REE pattern itself may reflect their chemical species in the solid and water phases. In general, REEs are not present as free aquo ions in natural terrestrial water, but mainly exist as dissolved and surface complexes in aqueous and particulate phases, respectively, due to their large ionic potential (i.e., ionic charge/ radius) (Stumm and Morgan, 1996; Gaillardet et al., 2003; 

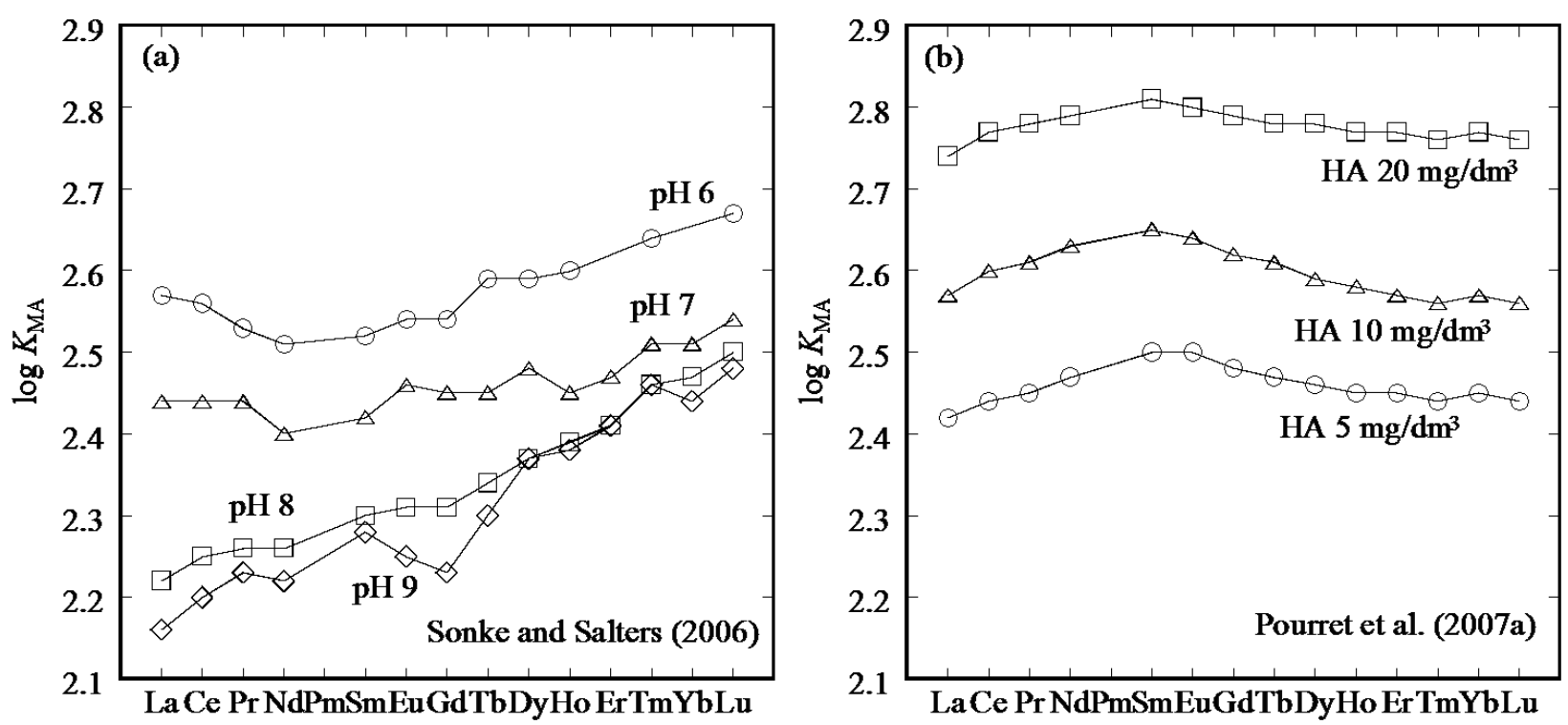

Fig. 1. REE patterns of $\log K_{M A}$ for HA. (a) Leonardite coal humic acid (LHA) using the EDTA competition method coupled with the capillary electrophoresis-ICP-MS technique (Sonke and Salters, 2006). (b) Purified Aldrich humic acid (AHA) using the ultrafiltration method (Pourret et al., 2007a).

Johannesson et al., 2004; Tang and Johannesson, 2005). Since relative stabilities of these complexes can be different over the REE series, the shape of the REE pattern contains information about the REE species in water and on particulate matter.

Organic matter plays an important role as a carrier of REEs in natural terrestrial water as is similar to $\mathrm{Fe}-\mathrm{Mn}$ hydroxides and clay minerals (Tanizaki et al., 1992; Ingri et al., 2000). Humic substances (HSs) such as fulvic and humic acids (FA and HA) are typical organic matter, which interacts with metal ions in natural terrestrial water (Tipping, 2002). Although many previous studies have been conducted on the REE-HS interaction, most studies on the stability constants of REE-HS complexes were reported for a single REE, especially Eu (Torres and Choppin, 1984; Bidoglio et al., 1991; Moulin et al., 1992; Takahashi et al., 1994; Lead et al., 1998; Glaus et al., 2000; Dong et al., 2002; Kubota et al., 2002; Tochiyama et al., 2004). Reports for all (or several) REEs were much less than those for a single REE (Takahashi et al., 1997; Yamamoto et al., 2005; Sonke and Salters, 2006; Pourret et al., 2007a; Stern et al., 2007), and relative stabilities among REEs (i.e., REE pattern of the stability constants) are not consistent among these studies.

Yamamoto et al. (2005) and Pourret et al. (2007a) reported that REE patterns of $\log \beta_{\mathrm{M}-\mathrm{HS}}$ and $\log K_{\mathrm{MA}}$ show a maximum around middle REEs (MREE), as shown in Fig. $1 \mathrm{~b}$. In this paper, the notation $\beta_{\mathrm{M}}$ represents an apparent stability constant, and the subscripts M and M-HS denote a metal ion and a complex between metal ions and
HS. $K_{\mathrm{MA}}$ is a REE-HS interaction parameter in Tipping's "Humic Ion-Binding Model VI" (Tipping, 1998), hereafter referred to as Model VI. In contrast to these two studies, Takahashi et al. (1997), Sonke and Salters (2006), and Stern et al. (2007) reported that REE patterns of $\log \beta_{\mathrm{M}-\mathrm{HS}}$ show a monotonous increase with increasing atomic number (Fig. 1a). Although $\beta_{\mathrm{M}-\mathrm{HS}}$ changes with variation in electrostatic effects, differences in the REE pattern of intrinsic $\log K_{\mathrm{MA}}$ cannot be explained by variation in electrostatic effects (Fig. 1). Sonke (2006), Pourret et al. (2007a), and Stern et al. (2007) suggested that change in the main binding sites of REEs in HSs may cause variation in the REE pattern of the intrinsic stability constants reported in previous studies.

As suggested from the linear free-energy relationship (LFER) of REE complexes between polyelectrolytes and simple ligands, the REE pattern of the polyelectrolytes' stability constants reflects the main binding sites of REEs in a given ligand (Byrne and Kim, 1990; Stumm, 1992; Takahashi et al., 2005). In general, distinguishing the main binding site of metal ions in a heterogeneous polyelectrolyte is difficult without employing spectroscopic techniques. The binding sites of REEs in HSs, however, may be evaluated by comparing REE patterns of the stability constants of REE complexes between HSs and a variety of simple ligands based on the LFER (Stumm, 1992). Some approaches to clarify the main binding sites of REEs in heterogeneous polyelectrolytes were applied to marine organic matter and bacteria (Byrne and Kim, 1990; Takahashi et al., 2005). Similar to these polyelectrolytes, 
HSs also has many functional groups (e.g., carboxylic and phenolic $\mathrm{OH}$ groups) that can bind to metal ions (Tipping, 2002; Ritchie and Perdue, 2003). Yamamoto et al. (2005) and Pourret et al. (2007a) suggested that the main binding sites of REEs in HSs are carboxylic functional groups under their experimental conditions due to the similarity of the REE pattern of the stability constants between REE-HS complexes and simple carboxylates. On the other hand, Sonke and Salters (2006) and Stern et al. (2007) under their experimental conditions indicated that chelating sites are the main binding sites of REEs in HSs, suggested by the steep slope of the REE pattern of $\log \beta_{\mathrm{M}-\mathrm{HS}}$, similar to aminopolycarboxylates such as nitrilotriacetic acid (NTA) and ethylenediaminetetraacetic acid (EDTA).

Some experimental studies on Eu-HA interaction indicated that the apparent binding constant of Eu with HA depends on the Eu loading level to HA (Hummel et al., 2000; Kubota et al., 2002; Tochiyama et al., 2004). Hummel et al. (2000) demonstrated that the experimental binding constants of Eu-HA complexes, which were reported by Caceci (1985) and Glaus et al. (2000), decrease with an increase in the Eu loading level. Kubota $e t$ al. (2002) determined $\beta_{\mathrm{M}-\mathrm{HS}}$ of selected metal ions $\left(\mathrm{Eu}^{3+}\right.$, $\mathrm{Ca}^{2+}, \mathrm{Fe}^{2+}, \mathrm{Fe}^{3+}$, and $\mathrm{NpO}_{2}^{+}$) with $\mathrm{HA}$ and synthetic polyacrylic acid (PAA) at various metal loading levels by employing solvent extraction method. The study shows that $\beta_{\mathrm{M}-\mathrm{HS}}$ decreased with an increase in the metal loading level. In contrast, $\beta_{\mathrm{M}-\mathrm{PAA}}$ remained constant at various metal loading levels. These results suggested that HSs contain minor but more stable binding sites to metal ions, which are not present in PAA (Kubota et al., 2002). Hummel et al. (2000) also indicated that variation in the binding constants of Eu-HA complexes according to the metal loading level can be understood by assuming a high concentration of lower-affinity sites and a low concentration of higher-affinity sites. In their study, it was proposed that a simple two-site model can explain the variation in experimental binding constants for a single element as a function of the metal loading level, and that a phenolic $\mathrm{OH}$ group can be a minor but higher affinity site. It is expected that similar change also occurs in the system containing all REEs, where the change in the binding sites is reflected in the REE pattern of the intrinsic stability constants for HS. Therefore, a change in the main binding sites of REEs with the REE loading level is the most possible factor that can explain the different REE patterns of stability constants among previous studies (Takahashi et al., 1997; Yamamoto et al., 2005; Sonke and Salters, 2006; Pourret et al., 2007a; Stern et al., 2007). However, experimental evaluation has not been performed for the systematic changes in the REE pattern of the intrinsic stability constants for HSs at various REE loading levels, which is the main topic in this study. The REE loading level, which is expressed by the total concentration of REE-HS complexes $\left(\mathrm{mol} / \mathrm{dm}^{3}\right)$ normalized by that of dissociated ligands (equiv $/ \mathrm{dm}^{3}$ ) in HSs, is not consistent among the aforementioned studies. Yamamoto et al. (2005) conducted solvent extraction experiments at 1.0 mmol/equiv, whereas Pourret et al. (2007a) conducted ultrafiltration experiments at a range of 40 to $230 \mathrm{mmol} /$ equiv. Takahashi et al. (1997) conducted solvent extraction experiments using radioisotopes at less than $10^{-5}$ mmol/equiv. Sonke and Salters (2006) conducted their experiments at a range of 0.0035 to $2.5 \mathrm{mmol} / \mathrm{equiv}$ by capillary electrophoresis-inductively coupled plasma mass spectrometry (CE-ICP-MS).

Hence, comparison of relative shapes of the REE patterns of the intrinsic stability constants for HSs $\left(K_{\mathrm{MA}}\right)$ reported in previous studies is necessary in terms of the REE loading level (Sonke, 2006; Pourret et al., 2007a). Therefore, in this study, we determined $K_{\mathrm{MA}}$ of all REEs (except for Pm) with HA for Model VI (Tipping, 1998) at a wide range of REE loading levels of 0.073 to $56 \mathrm{mmol} /$ equiv, and discussed the effect of the loading level on the relative shape of the REE pattern of $\log K_{\mathrm{MA}}$ based on the LFER between REE-HA complexes and various carboxylates. Two different methods, solvent extraction and equilibrium dialysis, were employed for determining $K_{\mathrm{MA}}$.

In addition, the influence of $\mathrm{Fe}$ and $\mathrm{Al}$ on REE-HA complexation should be discussed. HSs originally contain $\mathrm{Fe}$ and $\mathrm{Al}$ at a high concentration depending on the extraction and purification methods of HSs (Stookey, 1970; Kim et al., 1990; Yamamoto et al., 2009). Yamamoto et al. (2009) reported that Fe exists as ferric carboxylate complexes in SRHA, which inhibits complexation of target ions and HA. Aluminum can also inhibit complexation of trace metal ions and HA (Tipping, 2002). It is expected that the degree of the inhibition of REE-HA complexation by these metal ions can be changed depending on experimental methods and sources of HA employed in the previous studies on REE-HA complexation (Takahashi et al., 1997; Yamamoto et al., 2005; Sonke and Salters, 2006; Pourret et al., 2007a; Stern et al., 2007). In this study, the stability constants of REEHA complexes were evaluated using the total metal loading level, which is total concentration of REE-, Fe-, and Al-HA complexes $\left(\mathrm{mol} / \mathrm{dm}^{3}\right)$ normalized by that of dissociated ligands (equiv/ $/ \mathrm{dm}^{3}$ ) in HA.

\section{Materials AND Methods}

\section{Humic substances}

Standard Suwannee River humic acids (SRHA: IHSS code $1 \mathrm{~S} 101 \mathrm{H})$ were obtained from International Humic Substances Society (IHSS) (Ritchie and Perdue, 2003). HSs are classified into FA, HA, and humin according to 
their solubility at different $\mathrm{pH}$ values (Tipping, 2002). The degree of dissociation of SRHA as a function of $\mathrm{pH}$ was determined by Ritchie and Perdue (2003) by pH titration. The experimental titration data were used for determination of concentration of dissociated functional groups in SRHA at various $\mathrm{pH}$ values in this study.

Concentrations of $\mathrm{Fe}$ and $\mathrm{Al}$ in SRHA, Aldrich humic acid (AHA), and purified AHA were determined by inductively coupled plasma-mass spectrometry (ICP-MS, Agilent 7500). AHA was used for determination of Fe and $\mathrm{Al}$ concentrations to estimate the influence of $\mathrm{Fe}$ and $\mathrm{Al}$ on REE-HA complexation in previous studies, not for determination of stability constants of REEs. Fifty $\mathrm{mg}$ of dried $\mathrm{HA}$ was decomposed with the addition of $\mathrm{HNO}_{3}$ and $\mathrm{H}_{2} \mathrm{O}_{2}$ in a Teflon ${ }^{\circledR}$ container at $180^{\circ} \mathrm{C}$. After evaporation, the residue was redissolved using $2 \% \mathrm{HNO}_{3}$. The ICP-MS measurement was carried out in collision cell mode using $\mathrm{He}$ gas at a flow rate of $3 \mathrm{~mL} / \mathrm{min}$ with the addition of ${ }^{72} \mathrm{Ge}$ as an internal standard. Analytical precision was better than 6 and $2 \%$ for $\mathrm{Fe}$ and $\mathrm{Al}$, respectively.

\section{Solvent extraction}

In order to determine the $\beta_{\mathrm{M}-\mathrm{HS}}$, a solvent extraction method using di(2-ethylhexyl)phosphoric acid (DEHP) was employed to extract free REE ions into organic phases. DEHP is a selective extractant for trivalent cations, where three dimers of DEHP extract one free trivalent cation into the organic phase. DEHP was purified before use, according to Peppard et al. (1957). Toluene was used as a solvent of the organic phase in this study. The partitioning ratio between aqueous and organic phases is determined by a balance between complexation with ligands including HSs in the aqueous phase and extraction by DEHP to the organic phase. The $\beta_{\mathrm{M}-\mathrm{HS}}$ of each REE was determined by a comparison between the partitioning ratios with and without HSs. In this study, the solvent extraction method that generally followed previous studies (Torres and Choppin, 1984; Takahashi et al., 1997), coupled with ICP-MS (Thermo Fisher Scientific, PQ-3), was used instead of the radioisotope tracer technique, due to a lack of proper radioisotopes for many REEs. The solvent extraction method using stable isotopes of REEs requires the reduction of the total concentration of REEs relative to HSs and DEHP. In addition, the differences among REEs in terms of the extraction efficiencies by DEHP may inhibit simultaneous measurement of partitioning ratios for all REEs in one solvent extraction system. Therefore, REEs were divided into three groups: group I ( $\mathrm{La}, \mathrm{Ce}, \mathrm{Pr}, \mathrm{Nd}, \mathrm{Sm}$, and $\mathrm{Eu}$ ), group II (Eu, Gd, Tb, Dy, Ho, and Y), and group III (Ho, Er, $\mathrm{Tm}, \mathrm{Yb}$, and $\mathrm{Lu})$. To confirm the effects of competition among coexisting REEs, we also determined the $\beta_{\mathrm{M}-\mathrm{HS}}$ at pH 4.7 independently for $\mathrm{La}, \mathrm{Eu}$, and Ho. The total con- centrations of REEs in each group were $10-100 \mu \mathrm{g} / \mathrm{dm}^{3}$ $(60-700 \mathrm{nM})$, while that of HSs was $0-200 \mathrm{mg} / \mathrm{dm}^{3}(0-$ 1.0 mequiv $/ \mathrm{dm}^{3}$ ).

The aqueous phase $\left(5 \mathrm{~mL}, \mathrm{I}=0.10 \mathrm{M}\right.$ by $\left.\mathrm{NaClO}_{4}\right)$ containing one REE group, HS, and buffer reagent was mixed with the organic phase $(5 \mathrm{~mL})$ containing DEHP. The sample was shaken for $72 \mathrm{~h}$, which is long enough to reach equilibrium in the aqueous-organic distribution of REEs (Torres and Choppin, 1984; Takahashi et al., 1997). The extraction procedures were carried out in polypropylene test tubes. Acetic acid was used as a buffer agent to maintain $\mathrm{pH}$ at 4.7. The organic phase was preequilibrated by the buffer solution so that $\mathrm{pH}$ of the aqueous phase is not altered. The removal of HSs from the aqueous phase was monitored by the absorbance at 400 $\mathrm{nm}$ before and after the solvent extraction. The recovery of HSs was almost constant at $103 \pm 4 \%$, showing that HS loss from the aqueous phase is negligible. The two phases were separated to determine the partitioning ratio of REEs. After determining the final $\mathrm{pH}$, the aqueous phase was evaporated with the addition of $\mathrm{HNO}_{3}$ and $\mathrm{H}_{2} \mathrm{O}_{2}$ in a Teflon ${ }^{\circledR}$ container to decompose HSs, which can affect the intensity of REE signals in ICP-MS. The REEs in the residue were redissolved using $2 \% \mathrm{HNO}_{3}$ for ICPMS measurement. The REEs in the organic phase were back-extracted to $30 \%$ hydrochloric acid by shaking for $24 \mathrm{~h}$. The hydrochloric acid was evaporated and the REEs in the residue were redissolved using $2 \% \mathrm{HNO}_{3}$ for ICPMS measurement. The REE concentrations were determined using ${ }^{115} \mathrm{In}$ and ${ }^{209} \mathrm{Bi}$ as internal standards. Detection limits were less than $5 \mathrm{ng} / \mathrm{kg}$ for all REEs. Analytical precision was better than 5\% RSD (relative standard deviation) for all REEs. Average recovery for all REEs through the solvent extraction experiment was $98 \pm 10 \%$.

\section{Equilibrium dialysis}

The equilibrium dialysis experiment was conducted in two cubic chambers made of acrylic plastic, which were separated by a membrane. Each chamber has a $40 \mathrm{~mm}$ long edge, whereas the membrane area in the cell is 177 $\mathrm{mm}^{2}$ (circle with a radius of $7.5 \mathrm{~mm}$ ). The molecular weight cut-off (MWCO) of the membrane employed in this study was $1000 \mathrm{Da}\left(\right.$ Spectra/Por $\left.{ }^{\circledR}\right)$. The source cell was filled with a solution including all REE ions, while the receiver cell was filled with a REE free solution. The concentration of each REE ion ranged from 0.4 to 400 $\mu \mathrm{g} / \mathrm{dm}^{3}$. The HS employed in the dialysis experiment was SRHA (mean MW: $4260 \mathrm{Da}$ ) (Reid et al., 1990), the concentration of which in the receiver cell was adjusted to 0 , 15 , or $50 \mathrm{mg} / \mathrm{dm}^{3}$. Ionic strength was adjusted at 0.020 and $0.10 \mathrm{M}$ by $\mathrm{NaClO}_{4}$, while the $\mathrm{pH}$ value was 4.7 . To avoid a large discrepancy in the REE distribution between the two cells, citrate (MW: 192.13 Da) was used as a competitive ligand to maintain the REE distribution (Glaus et 

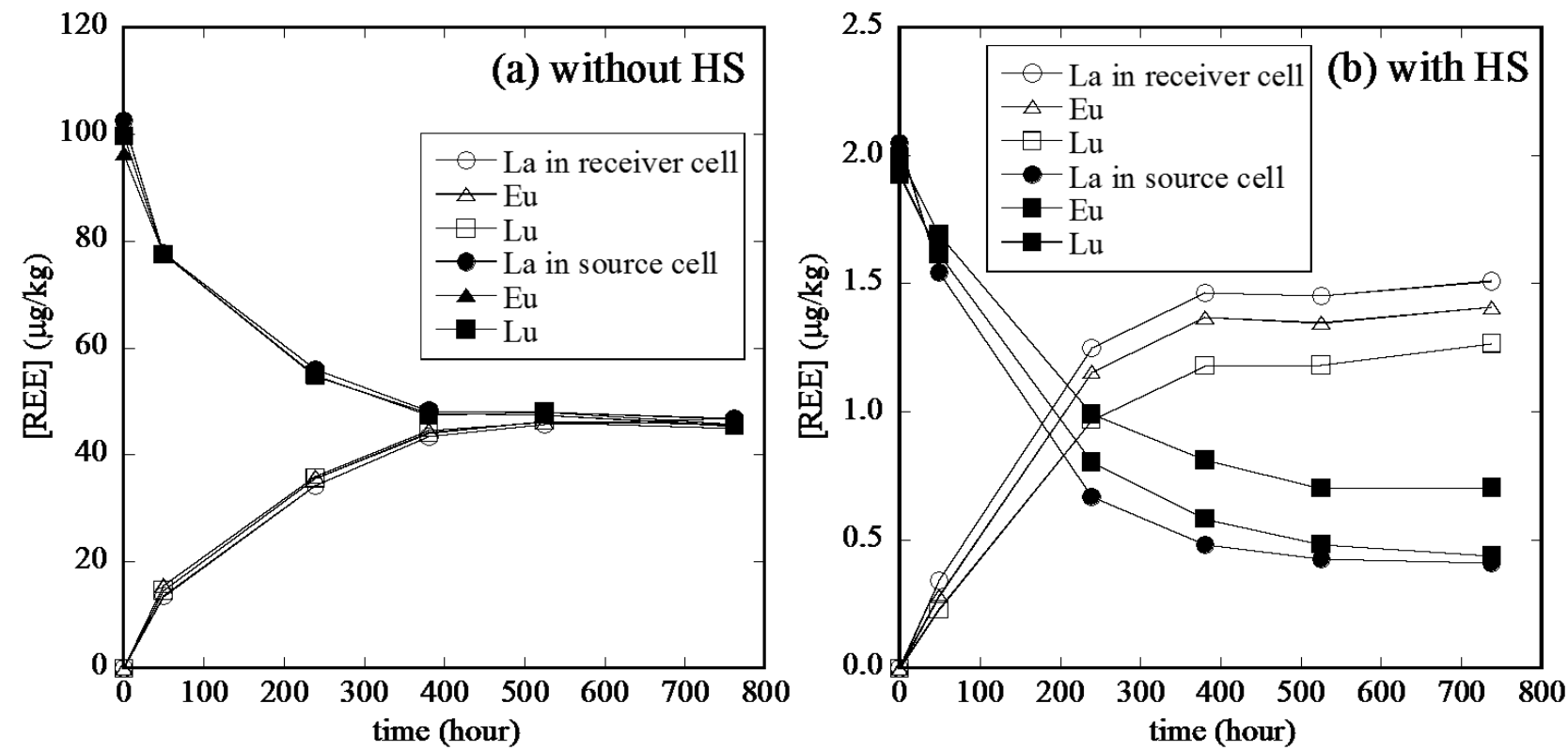

Fig. 2. REE concentrations as a function of elapsed time in the source and receiver cells in the absence and presence of HA for equilibrium dialysis experiments.

al., 1995a). The absence of a competitive ligand can make REE measurement difficult due to the low REE concentration in the source or in the HS-free cell. The solution in each cell was stirred using a magnetic stirrer at a constant speed for $500 \mathrm{~h}$. This period was determined in a preliminary experiment, where the REE concentration in each cell was measured at various elapsed times to ascertain equilibrium time, which was found to be $500 \mathrm{~h}$ (Fig. 2). After $500 \mathrm{~h}$, the final HA concentration of the solution in each cell was determined by the absorbance at 400 $\mathrm{nm}$ using a spectrophotometer. After the determination of the final $\mathrm{pH}$, the solution was evaporated with the addition of $\mathrm{HNO}_{3}$ and $\mathrm{H}_{2} \mathrm{O}_{2}$ in a Teflon ${ }^{\circledR}$ container to decompose HSs, as was explained above. After evaporation, the residue was redissolved using $2 \% \mathrm{HNO}_{3}$ and led into a column filled with AG50W-X8 (cation exchange resin) to preconcentrate and separate $\mathrm{REE}^{3+}$ from $\mathrm{Na}^{+}$. The recovered solution from the column was evaporated and redissolved using $2 \% \mathrm{HNO}_{3}$. The REE in the $2 \%$ $\mathrm{HNO}_{3}$ solution was measured by ICP-MS (Thermo Fisher Scientific PQ-3 or Agilent 7500), as described previously. Average recovery for all REEs through the equilibrium dialysis experiment was $93 \pm 8 \%$.

\section{Theory of Stability Constant Determination}

\section{Solvent extraction}

The complexation reaction of HSs with a metal ion $\left(\mathrm{M}^{z+}\right)$ can be expressed as

$$
\mathrm{M}^{z+}+\mathrm{A} \leftrightarrow \mathrm{MA},
$$

and the apparent stability constant, $\beta_{\mathrm{M}-\mathrm{HS}}$, is expressed as

$$
\beta_{\mathrm{M}-\mathrm{HS}}=\frac{[\mathrm{MA}]}{\left(\left[\mathrm{M}^{z+}\right][\mathrm{A}]\right)},
$$

where $z$ and A are the charges of the metal ion and the concentration of dissociated ligand of HSs, respectively. We assume that a single REE ion is bound to a single site in HSs. The relationship between $\beta_{\mathrm{M}-\mathrm{HS}}$ and the partitioning ratio of the solvent extraction system can be expressed as

$$
D_{0}\left(1 / D_{2}-1 / D_{1}\right)=\beta_{\mathrm{M}-\mathrm{HS}}[\mathrm{A}]
$$

where $D_{0}$ is the partitioning ratio without any aqueous ligands at lower pH. $D_{1}$ is the partitioning ratio in the presence of buffer anions at a $\mathrm{pH}$ value at which $\beta_{\mathrm{M}-\mathrm{HS}}$ is obtained, while $D_{2}$ is the partitioning ratio with HS. According to Torres and Choppin (1984), $D_{0}, D_{1}$, and $D_{2}$ are obtained in the solvent extraction system as follows:

$\frac{1}{D_{0}}=\left[\mathrm{M}^{z+}\right]_{\mathrm{aq}} /\left[\mathrm{M}\left\{(\mathrm{DEHP})_{2}\right\}_{z}\right]_{\mathrm{org}}$ 


$$
\begin{aligned}
\frac{1}{D_{1}} & =\left(\left[\mathrm{M}^{z+}\right]_{\mathrm{aq}}+[\mathrm{MB}]_{\mathrm{aq}}\right) /\left[\mathrm{M}\left\{(\mathrm{DEHP})_{2}\right\}_{z}\right]_{\mathrm{org}} \\
\frac{1}{D_{2}} & =\left(\left[\mathrm{M}^{z+}\right]_{\mathrm{aq}}+[\mathrm{MA}]_{\mathrm{aq}}+[\mathrm{MB}]_{\mathrm{aq}}\right) /\left[\mathrm{M}\left\{(\mathrm{DEHP})_{2}\right\}_{z}\right]_{\mathrm{org}} \\
& =\frac{1}{D_{1}}+[\mathrm{MA}]_{\mathrm{aq}} /\left[\mathrm{M}\left\{(\mathrm{DEHP})_{2}\right\}_{z}\right]_{\mathrm{org}}
\end{aligned}
$$

where $_{\text {org }}$ and ${ }_{\mathrm{aq}}$ indicate organic and aqueous phases, respectively, and $\mathrm{B}$ indicates other ligands such as $\mathrm{OH}^{-}$, $\mathrm{CO}_{3}{ }^{2-}$, and buffer anions in the aqueous phase. We assume that a trace amount of metal ions does not influence the equilibrium of proton dissociation of HSs. The extraction reaction of metal ions by DEHP can be expressed as

$$
\begin{aligned}
& \left(\mathrm{M}^{z+}\right)_{\mathrm{aq}}+z\left\{\mathrm{H}(\mathrm{DEHP})_{2}\right\}_{\mathrm{org}} \\
& \leftrightarrow z\left(\mathrm{H}^{+}\right)_{\mathrm{aq}}+\left(\mathrm{M}\left\{(\mathrm{DEHP})_{2}\right\}_{z}\right)_{\mathrm{org}}
\end{aligned}
$$

When $[\mathrm{M}]_{\mathrm{t}}$ (which is the total concentration of $\mathrm{M}$ in the aqueous phase) is small enough, the concentration of free $(\mathrm{DEHP})_{2}$ in the organic phase does not change by the formation of $\left(\mathrm{M}\left\{(\mathrm{DEHP})_{2}\right\}_{z}\right)_{\text {org }}$ species in the organic phase. On the other hand, $D_{0}$ can be obtained from the extraction properties of DEHP as

$$
\log D_{0}=a \cdot \mathrm{pH}+b \cdot \log \left(\left[(\mathrm{DEHP})_{2}\right]_{\mathrm{org}}\right)+\log K_{\mathrm{ex}},
$$

where $a$ and $b$ are ideally equal to $z . K_{\mathrm{ex}}$ is the extraction constant defined as

$$
K_{\mathrm{ex}}=\frac{\left[\mathrm{H}^{+}\right]_{\mathrm{aq}}^{z}\left[\mathrm{M}\left\{(\mathrm{DEHP})_{2}\right\}_{z}\right]_{\mathrm{org}}}{\left[\mathrm{M}^{z+}\right]_{\mathrm{aq}}\left[\mathrm{H}\left\{(\mathrm{DEHP})_{2}\right\}_{z}\right]_{\mathrm{org}}^{z}} .
$$

$K_{\text {ex }}$ and the coefficients, $a$ and $b$, were determined experimentally by solvent extraction in the absence of any HSs below pH 3, where hydrolysis and carbonate complexation of REEs are negligible. The ionic strength was $0.10 \mathrm{M}$ with $\mathrm{NaClO}_{4}$, including contributions from $\mathrm{HClO}_{4}$.

In this study, $a$ and $b$ were determined as $2.99 \pm 0.07$ and $2.83 \pm 0.08$, respectively, except for Ce. For Ce, $a$ and $b$ were 2.77 and 2.51 , respectively, clearly lower than those of other REEs. The reason for these lower values is not clear at present, but it could be due to the formation

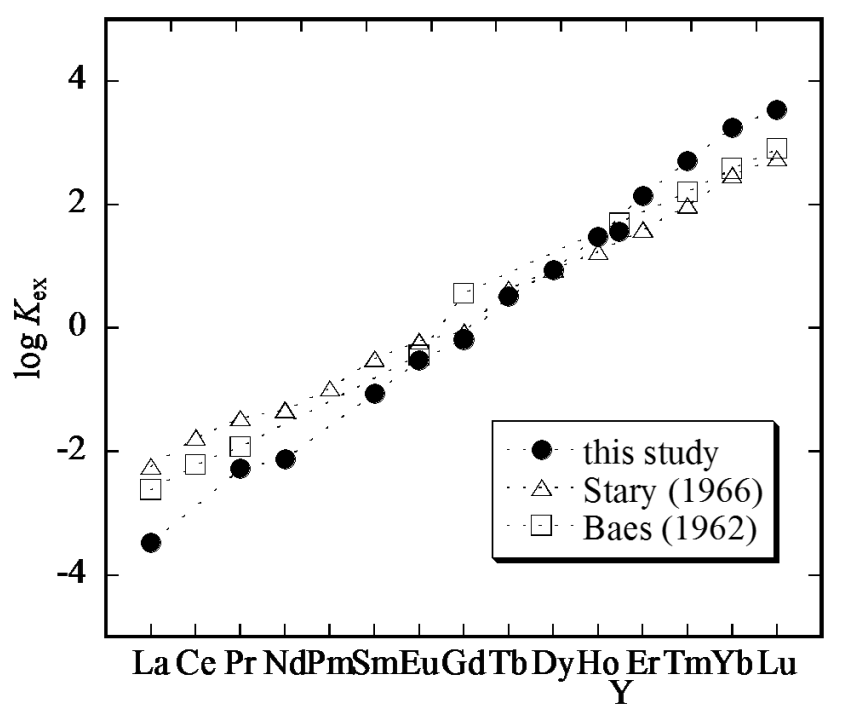

Fig. 3. REE patterns of $\log K_{\text {ex }}$ by DEHP in the solvent extraction experiment.

of some Ce(IV) species in the experimental system. The extraction constants of REEs are shown in Fig. 3 with reference values reported in Baes (1962) and Stary (1966).

$D_{2}$ depends on [A] (equiv/ $/ \mathrm{dm}^{3}$ ), which can be determined from the proton exchange capacity of HSs, and the degree of dissociation at each $\mathrm{pH}$ determined by $\mathrm{pH}$ titration (Ritchie and Perdue, 2003). $\beta_{\mathrm{M}-\mathrm{HS}}$ of HSs complex is an apparent value, which depends on $\mathrm{pH}$, ionic strength, and the metal loading level (i.e., [MA]/[A]) (Hummel et al., 2000; Kubota et al., 2002; Tochiyama et al., 2004; Yamamoto et al., 2005).

\section{Equilibrium dialysis}

The complexation reactions of metal ions occurring in the dialysis experiment can be expressed by the following equations:

$$
\begin{aligned}
& \mathrm{M}^{z+}+\mathrm{A} \leftrightarrow \mathrm{MA} \\
& \mathrm{M}^{z+}+\text { citrate } \leftrightarrow \mathrm{M} \text { - citrate. }
\end{aligned}
$$

Here, $\beta_{\mathrm{M} \text {-citrate }}$ of REEs is taken from Martell et al. (2003). The total concentrations of metal ions in each cell can be evaluated using

$$
\begin{aligned}
& {[\mathrm{M}]_{\text {source }}=\left[\mathrm{M}^{z+}\right]+[\mathrm{M} \text { - citrate }],} \\
& {[\mathrm{M}]_{\text {receiver }}=\left[\mathrm{M}^{z+}\right]+[\mathrm{M} \text { - citrate }]+[\mathrm{MA}] .}
\end{aligned}
$$

A preliminary experiment described earlier in the text 
demonstrated that REE concentrations in the source cell without HA were equal to those in the receiver cell after $500 \mathrm{~h}$ (Fig. 2). This fact suggests that REE-citrate complexes and free REE ions can pass through the membrane used in this study. Therefore, the concentrations of free REE ions are expected to be identical between the source and receiver cells even in the presence of HA and the same REE-citrate complexes. In such a case, the concentration of REE-HA complexes can be expressed as

$$
[\mathrm{M}]_{\text {receiver }}-[\mathrm{M}]_{\text {source }}=[\mathrm{MA}]_{\text {receiver }} \text {. }
$$

The concentration of dissociated ligands of HA in the receiver cell was determined from the proton exchange capacity of HA and the degree of dissociation at each $\mathrm{pH}$ determined by $\mathrm{pH}$ titration (Ritchie and Perdue, 2003). Consequently, $\beta_{\mathrm{M}-\mathrm{HS}}$ of all REEs can be determined by Eq. (2). Although MWCO of the membrane (1000 Da) is smaller than the mean MW of SRHA (4260 $\pm 280 \mathrm{Da})$ (Reid et al., 1990), a small amount of HA in the receiver cell with a relatively smaller MW can infiltrate the membrane to the source cell. The effect of infiltrated HA (less than $10 \%$ in our experiments) into the source cell was corrected according to Glaus et al. (1995a).

Formation of ternary complexes consisting of HSs, REEs, and citrate is a potential problem for the equilibrium dialysis experiment (Dierckx et al., 1994; Glaus et al., 1995b), which can cause overestimation of $\beta_{\mathrm{M}-\mathrm{HS}}$. Furthermore, the degree of overestimation of $\beta_{\mathrm{M}-\mathrm{HS}}$ becomes larger with an increase in the concentration of the competitive ligand (Glaus et al., 1995b), which is citrate in this study. Formation of ternary complexes involving $\mathrm{Eu}^{3+}, \mathrm{HS}$, and several low-molecular-weight ligands (monocarbonates, oxalates, acethylaceatates, iminodiaceatates, and hydroxides) have been reported (Dierckx et al., 1994). $\beta_{\mathrm{M}-\mathrm{HS}}$ of $\mathrm{Co}^{2+}$ with FA increases with the concentration of oxalates as a competitive ligand due to the formation of the ternary complexes. A similar result was obtained for $\beta_{\mathrm{M}-\mathrm{HS}}$ of $\mathrm{UO}_{2}{ }^{2+}$ in the oxalate (MW: 90.0) system, but not for $\mathrm{UO}_{2}{ }^{2+}$ in the EDTA (MW: 292.2 Da) system due to the relatively large molecular size of EDTA (Glaus et al., 1995b). Furthermore, it has been indicated that a ternary complex does not form at a concentration of less than the critical concentration of the competitive ligand (Glaus et al., 1995b). Ternary complexes of REEs and HSs in a citrate (MW: 192.1 Da) system have not been reported. In this study, the concentration of citrate was within the range of $10^{-4.1}$ to $10^{-2.7} \mathrm{M}$, which is smaller than a critical concentration limit reported for oxalate (about $10^{-2.5} \mathrm{M}$ ). Since the possibility of the presence of a ternary complex in the citrate system must be lower than that in an oxalate system due to the larger MW of citrate, the formation of ternary complex of citrate was ignored in this study.
Table 1. Concentrations of $\mathrm{Fe}$ and $\mathrm{Al}$ in $\mathrm{HA}$

\begin{tabular}{lcccl}
\hline & SRHA & AHA & Purified AHA & \\
\hline Fe $(\mathrm{mg} / \mathrm{kg})$ & 780 & 5900 & 440 & This study \\
& $8830 *$ & $12207 * *$ & $360 * *$ & Previous studies \\
& & & & \\
$\mathrm{Al}(\mathrm{mg} / \mathrm{kg})$ & 320 & 1700 & 130 & This study \\
& & $2950 * *$ & $35 * *$ & Previous studies \\
\hline
\end{tabular}

*Stookey (1970); **Kim et al. (1990).

Purification procedure of Aldrich humic acid (AHA) was followed Kim et al. (1990). Any purification of SRHA was not conducted before use.

\section{RESULTS}

\section{Iron and $A l$ in $H A$}

Concentrations of Fe and $\mathrm{Al}$ in SRHA, AHA, and purified AHA were listed in Table 1. Our results are smaller than those in previous studies, except for purified AHA (Stookey, 1970; Kim et al., 1990). Even after purification, HA contains $\mathrm{Fe}$ at a high concentration.

\section{$\beta_{M-H S}$ determined by solvent extraction}

$\beta_{\mathrm{M}-\mathrm{HS}}$ for SRHA at $\mathrm{pH} 4.7$ determined as a function of the REE loading level according to Eqs. (3)-(9) are shown in Fig. 4. In the calculation of the REE loading level (i.e., [MA]/[A]), [MA] is defined as the summation of the concentrations of all REE-HS complexes in the experimental system, and [A] is the concentration of dissociated ligands in HA. To determine the REE loading level, we assume that REE-HS complexes are dominant species in the aqueous phase, since the complexes with buffer anions, hydroxides, and carbonates can be negligible under our experimental conditions. Following Eqs. (3)-(6), the total concentration of REE-HS complexes was determined experimentally as given below:

$$
[\mathrm{MA}]=\sum\left\{\left(\left[\mathrm{M}_{\mathrm{tot}}\right]_{\mathrm{aq}} \cdot \beta_{\mathrm{M}-\mathrm{HS}}[\mathrm{A}]\right) /\left(1+\beta_{\mathrm{M}-\mathrm{HS}}[\mathrm{A}]\right)\right\},
$$

where $\left[\mathrm{M}_{\mathrm{tot}}\right]_{\mathrm{aq}}$ denotes the total concentration of REEs in the aqueous phase (i.e., $\left[\mathrm{M}^{3+}\right]+[\mathrm{MA}]$ ). Thus, the REE loading level was calculated as a molar concentration ratio of [MA] to [A] based on Eq. (15).

$\log \beta_{\mathrm{M}-\mathrm{HS}}$ of SRHA decreased with an increase in the REE loading level at the lower REE loading region except for some LREEs ( $\mathrm{La}, \mathrm{Pr}$, and $\mathrm{Nd}$ ), whereas $\log \beta_{\mathrm{M}-\mathrm{HS}}$ is almost constant beyond an inflection point (Fig. 4). The inflection point of $\log \beta_{\mathrm{M}-\mathrm{HS}}$ of SRHA is around $1.5 \mathrm{mmol} /$ equiv. The variation in $\log \beta_{\mathrm{M}-\mathrm{HS}}$ with the REE loading level was observed in cases of injection of single and multiple REE(s) into the experimental system. This variation is consistent with previous studies on Eu-HA complexation (Hummel et al., 2000; Kubota et al., 2002; 

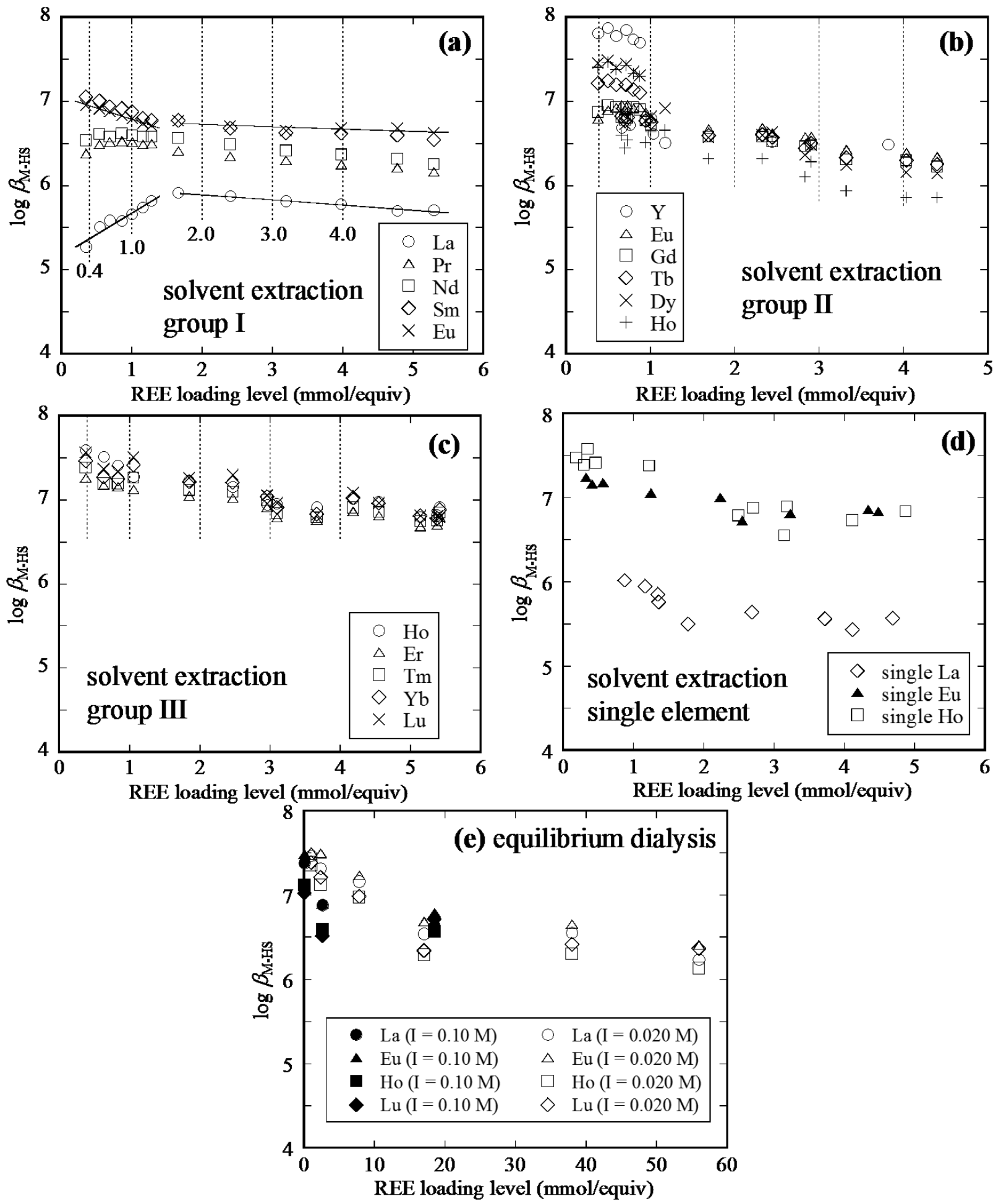

Fig. 4. $\log \beta_{M-H S}$ of SRHA determined using solvent extraction and equilibrium dialysis as a function of the REE loading level. $\log \beta_{M-H S}$ of REEs for (a) Group I; (b) Group II; (c) Group III; and (d) La, Eu, and Ho in a single REE system was found using the solvent extraction method. The approximated lines (solid lines) for La and Eu determined by least-squares approximation were given as examples. The broken lines denote the points of the REE loading level where representive $\beta_{M-H S}$ values were determined at 0.40, 1.0, 2.0, 3.0, and 4.0 mmol/equiv. (e) $\log \beta_{M-H S}$ of La, Eu, Ho, and Lu in a multi-REE system using equilibrium dialysis. 
Table 2. $\log \beta_{M-H S}$ and mean fit $\log K_{M A}$ for solvent extraction

\begin{tabular}{lcccccccc}
\hline & \multicolumn{5}{c}{$\log \beta_{\mathrm{M}-\mathrm{HS}}$} & & \multicolumn{2}{c}{$\log K_{\mathrm{MA}}$} \\
\cline { 2 - 5 } \cline { 9 - 10 } REE loading* & 0.4 & 1.0 & 2.0 & 3.0 & 4.0 & & mean fit & rmse \\
\hline $\mathrm{Y}$ & 7.50 & 7.73 & 6.59 & 6.51 & 6.44 & & 2.22 & 0.06 \\
$\mathrm{La}$ & 5.26 & 5.86 & 5.87 & 5.67 & 5.48 & & 2.02 & 1.12 \\
$\mathrm{Ce}$ & & & & & & & & \\
$\mathrm{Pr}$ & 6.34 & 6.68 & 6.35 & 6.15 & 5.95 & & 2.14 & 0.11 \\
$\mathrm{Nd}$ & 6.47 & 6.77 & 6.50 & 6.28 & 6.07 & & 2.16 & 0.08 \\
$\mathrm{Sm}$ & 6.93 & 7.05 & 6.70 & 6.51 & 6.32 & & 2.20 & 0.05 \\
$\mathrm{Eu}$ & 6.84 & 6.98 & 6.71 & 6.54 & 6.38 & & 2.21 & 0.03 \\
$\mathrm{Gd}$ & 6.90 & 6.94 & 6.62 & 6.44 & 6.27 & & 2.19 & 0.05 \\
$\mathrm{~Tb}$ & 7.24 & 7.10 & 6.60 & 6.45 & 6.30 & & 2.20 & 0.06 \\
$\mathrm{Dy}$ & 7.44 & 7.34 & 6.60 & 6.40 & 6.21 & & 2.19 & 0.09 \\
$\mathrm{Ho}$ & 7.42 & 7.32 & 6.34 & 6.14 & 5.94 & & 2.14 & 0.18 \\
$\mathrm{Er}$ & 7.09 & 7.13 & 6.19 & 6.00 & 5.81 & & 2.12 & 0.24 \\
$\mathrm{Tm}$ & 7.28 & 7.21 & 6.24 & 6.06 & 5.87 & & 2.13 & 0.21 \\
$\mathrm{Yb}$ & 7.39 & 7.34 & 6.32 & 6.13 & 5.95 & & 2.14 & 0.18 \\
$\mathrm{Lu}$ & 7.50 & 7.43 & 6.35 & 6.16 & 5.97 & & 2.15 & 0.17 \\
\hline
\end{tabular}

*Unit is mmol/equiv.

Table 3. $\log \beta_{M-H S}$ and mean fit $\log K_{M A}$ for equilibrium dialysis

\begin{tabular}{|c|c|c|c|c|c|c|c|c|c|c|c|}
\hline \multirow[b]{2}{*}{ REE loading* } & \multicolumn{9}{|c|}{$\log \beta_{\mathrm{M}-\mathrm{HS}}$} & \multicolumn{2}{|c|}{$\log K_{\mathrm{MA}}$} \\
\hline & 56 & 38 & 17 & 7.8 & 2.3 & 1.0 & 18 & 2.6 & 0.073 & mean fit & rmse \\
\hline $\mathrm{Y}$ & 6.05 & 6.16 & 6.30 & 6.98 & 7.08 & 7.37 & 6.51 & 6.55 & 7.00 & 2.40 & 0.10 \\
\hline $\mathrm{La}$ & 6.23 & 6.56 & 6.54 & 7.16 & 7.31 & 7.46 & 6.57 & 6.82 & 7.30 & 2.43 & 0.06 \\
\hline $\mathrm{Ce}$ & 6.35 & 6.65 & 6.66 & 7.25 & 7.42 & 7.53 & 6.70 & 6.92 & 7.45 & 2.46 & 0.04 \\
\hline $\operatorname{Pr}$ & 6.48 & 6.75 & 6.79 & 7.39 & 7.57 & 7.69 & 6.80 & 7.01 & 7.56 & 2.48 & 0.03 \\
\hline $\mathrm{Nd}$ & 6.44 & 6.70 & 6.75 & 7.35 & 7.54 & 7.66 & 6.75 & 6.95 & 7.53 & 2.48 & 0.04 \\
\hline $\mathrm{Sm}$ & 6.57 & 6.78 & 6.85 & 7.38 & 7.66 & 7.64 & 6.85 & 7.03 & 7.56 & 2.49 & 0.03 \\
\hline $\mathrm{Eu}$ & 6.41 & 6.65 & 6.69 & 7.23 & 7.49 & 7.51 & 6.72 & 6.84 & 7.42 & 2.47 & 0.05 \\
\hline $\mathrm{Gd}$ & 6.32 & 6.53 & 6.62 & 7.16 & 7.45 & 7.46 & 6.57 & 6.69 & 7.33 & 2.45 & 0.06 \\
\hline $\mathrm{Tb}$ & 6.14 & 6.38 & 6.42 & 7.02 & 7.21 & 7.34 & 6.47 & 6.58 & 7.16 & 2.42 & 0.08 \\
\hline Dy & 6.15 & 6.38 & 6.37 & 6.99 & 7.18 & 7.35 & 6.43 & 6.57 & 7.14 & 2.42 & 0.09 \\
\hline Ho & 6.13 & 6.30 & 6.29 & 6.97 & 7.12 & 7.35 & 6.50 & 6.54 & 7.06 & 2.42 & 0.10 \\
\hline $\mathrm{Er}$ & 6.12 & 6.25 & 6.29 & 6.93 & 7.08 & 7.32 & 6.52 & 6.45 & 6.99 & 2.41 & 0.11 \\
\hline $\mathrm{Tm}$ & 6.23 & 6.39 & 6.32 & 6.98 & 7.12 & 7.39 & 6.56 & 6.46 & 6.99 & 2.43 & 0.11 \\
\hline $\mathrm{Yb}$ & 6.30 & 6.39 & 6.38 & 7.02 & 7.19 & 7.42 & 6.73 & 6.49 & 7.04 & 2.44 & 0.10 \\
\hline $\mathrm{Lu}$ & 6.37 & 6.42 & 6.34 & 6.99 & 7.21 & 7.39 & 6.66 & 6.46 & 6.97 & 2.44 & 0.11 \\
\hline
\end{tabular}

*Unit is mmollequiv.

Tochiyama et al., 2004). In the case of the multi-REE system, however, $\log \beta_{\mathrm{M} \text {-HS }}$ of some LREEs (La, Pr, and $\mathrm{Nd}$ ) increase with the REE loading level at the lower REE loading region (Fig. 4a). In contrast, $\log \beta_{\text {La-HS }}$ decreases with an increase in the REE loading level at the lower REE loading region in the single REE system (Fig. 4d). The reason for the decrease in $\log \beta_{\mathrm{M}-\mathrm{HS}}$ of $\mathrm{La}, \mathrm{Pr}$, and $\mathrm{Nd}$ at the lower REE loading region in the multi-REE system is not clear at present, but may be due to competition among coexisting metal ions in the extraction process. Absolute values of $\beta_{\mathrm{M}-\mathrm{HS}}$ in both single- and multi-REE systems are roughly similar to each other at various REE loading levels. A lack of competition effect by coexisting metal ions at the lower REE loading region is confirmed for Eu and Ho (Fig. 4b).

To evaluate $\beta_{\mathrm{M}-\mathrm{HS}}$ of REEs at various REE loading levels, two linear approximations by least squares fitting were applied to experimental $\log \beta_{\mathrm{M}-\mathrm{HS}}$ data just below and above the apparent inflection point, which can separate the $\log \beta_{\mathrm{M}-\mathrm{HS}}$ dependence on the REE loading level into two regions. Examples are shown for $\mathrm{La}$ and $\mathrm{Eu}$ in Fig. 4a. Consequently, $\beta_{\mathrm{M}-\mathrm{HS}}$ of each REE was determined at the REE loading level of $0.4,1.0,2.0,3.0$, and 4.0 $\mathrm{mmol} / \mathrm{equiv}$ as listed in Table 2 . The uncertainty of $\beta_{\mathrm{M}-\mathrm{HS}}$ 
Table 4. Parameters of Model VI for HA (Tipping, 1998)

\begin{tabular}{lll}
\hline$n_{\mathrm{A}}$ & abundance of type A sites $(\mathrm{mol} / \mathrm{g})$ & $3.3 \times 10^{-3}$ \\
$n_{\mathrm{B}}$ & abundance of type B sites (mol/g) & $0.5 \times n_{\mathrm{A}}$ \\
$\mathrm{p} K_{\mathrm{A}}$ & intrinsic proton dissociation constant for type A sites & 4.1 \\
$\mathrm{p} K_{\mathrm{B}}$ & intrinsic proton dissociation constant for type B sites & 8.8 \\
$\Delta \mathrm{p} K_{\mathrm{A}}$ & distribution term that modifies $\mathrm{p} K_{\mathrm{A}}$ & 2.1 \\
$\Delta \mathrm{p} K_{\mathrm{B}}$ & distribution term that modifies $\mathrm{p} K_{\mathrm{B}}$ & 3.6 \\
$K_{\mathrm{MA}}$ & intrinsic equilibrium constant for metal binding at type A sites & adjustable \\
$K_{\mathrm{MB}}$ & intrinsic equilibrium constant for metal binding at type B sites & $3.391 \mathrm{log} K_{\mathrm{MA}}-1.15$ \\
$\Delta L K_{1}$ & distribution term that modifies log $K_{\mathrm{MA}}$ & 2.8 \\
$\Delta L K_{2}$ & distribution term that modifies the strength of bidentate and tridentate sites & 0.29 \\
$P$ & electrostatic parameter & -330 \\
$f_{\mathrm{prB}}$ & fraction of proton sites that can make bidentate sites & 0.5 \\
$f_{\mathrm{prT}}$ & fraction of proton sites that can make tridentate sites & 0.065 \\
$M$ & approximate molecular weight $(\mathrm{Da})$ & 15000 \\
$r$ & approximate molecular radius $(\mathrm{nm})$ & 1.72 \\
\hline
\end{tabular}

corresponds to an average of residual standard deviation between experimental data and the line obtained by approximation.

\section{$\beta_{M-H S}$ determined by equilibrium dialysis}

$\beta_{\mathrm{M}-\mathrm{HS}}$ was determined at $\mathrm{pH} 4.4 \pm 0.2$ with a variation in the REE loading level according to Eqs. (2), (12)-(14) as listed in Table 3 . Figure 4 e shows $\log \beta_{\mathrm{M}-\mathrm{HS}}$ of SRHA as a function of the REE loading level. Although the range of the REE loading level of equilibrium dialysis is wider than that of solvent extraction, the results of dialysis are qualitatively similar to those in the solvent extraction experiments. The inflection point for $\beta_{\mathrm{M}-\mathrm{HS}}$ at an ionic strength of $0.020 \mathrm{M}$ is around $15 \mathrm{mmol} /$ equiv, whereas that at an ionic strength of $0.10 \mathrm{M}$ (i.e., the ionic strength in the solvent extraction experiments) is less than 2.6 $\mathrm{mmol} / \mathrm{equiv}$, which is closer to the result of solvent extraction (which was $1.5 \mathrm{mmol} / \mathrm{equiv}$ ). Absolute values of $\beta_{\mathrm{M}-\mathrm{HS}}$ of the equilibrium dialysis experiments are roughly consistent with the results of solvent extraction (Fig. 4).

\section{Calculation of $K_{M A}$}

Obtained $\beta_{\mathrm{M}-\mathrm{HS}}$ values were converted into the $K_{\mathrm{MA}}$ values defined in Model VI (Tipping, 1998) using Windermere Humic Aqueous Model ver. 6.0 (WHAM6), which is a software for speciation calculation of metal ions in natural waters, by excluding the electrostatic term in the experimental $\beta_{\mathrm{M}-\mathrm{HS}}$. This procedure is essential to compare our data with the data in previous studies by other researchers, where only $K_{\mathrm{MA}}$ values were reported. Modeling strategies consist of using generic parameters (Table 4) and adjusting $\log K_{\mathrm{MA}}$ for all REEs in the experiment simultaneously. Details in calculation of $K_{\mathrm{MA}}$ are described in Appendix 1. The best-fit $\log K_{\mathrm{MA}}$ for each REE was obtained when the sum of the squares of the difference between the observed and calculated fraction of REEs bound to HA (\%) at a given REE loading level is at a minimum. Goodness of fitting for REE-HA binding was evaluated by the root mean square error (rmse) of the regression, as given below:

rmse

$=\sqrt{\frac{\sum\left\{\left(f(\mathrm{REE}-\mathrm{HA})_{\text {calculated }}-f(\mathrm{REE}-\mathrm{HA})_{\text {observed }}\right)^{2}\right\}}{n}}$,

where $n$ is the number of data points, and $f$ (REE-HA) is the percentage of REE bound to HA. Examples for La, $\mathrm{Eu}, \mathrm{Ho}$, and Lu are illustrated in Figs. 5 and 6, and mean fitted $\log K_{\mathrm{MA}}$ values for all REEs are reported in Tables 2 and 3. The data consist of four sets in the solvent extraction experiments (one of multi-REE and three of single-REE experiments) and one set for the equilibrium dialysis (multi-REE experiment).

As indicated by the obvious difference between observed and calculated fraction of REE-HA complexes, the mean fit by Model VI is not accurate for some REEs, such as La (Figs. 5a and e). In the case of the multi-REE system of the solvent extraction experiment, the rmse values for HREEs are clearly larger than those for LREEs and MREEs, except for La (Table 2). In the case of the single-REE system, the rmse values for $\mathrm{La}, \mathrm{Eu}$, and Ho are larger than those in the multi-REE system. The rmse values for HREEs in the equilibrium dialysis experiment are slightly larger than those for LREEs and MREEs. Goodness of fitting of REE-HA binding for the equilibrium dialysis (Fig. 6) is better than that for the solvent extraction.

The difference between the observed and calculated fraction of REE-HA complexes may be caused by employing $K_{\mathrm{MA}}$ values fixed at various REE loading levels. 

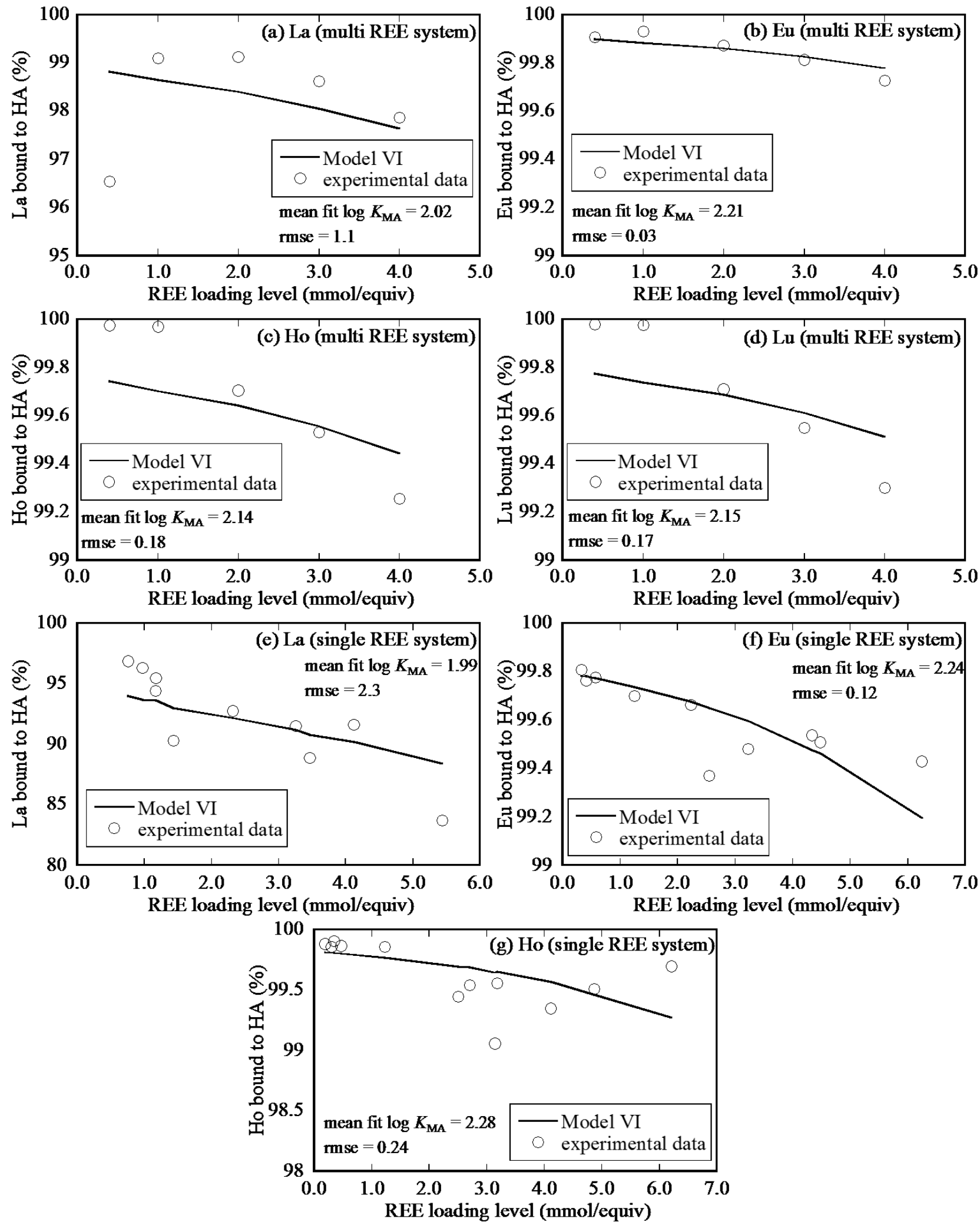

Fig. 5. Fraction of REEs bound to HA for multi and single REE systems using solvent extraction. Open symbols are experimental values, while a solid line corresponds to values calculated by Model VI. 

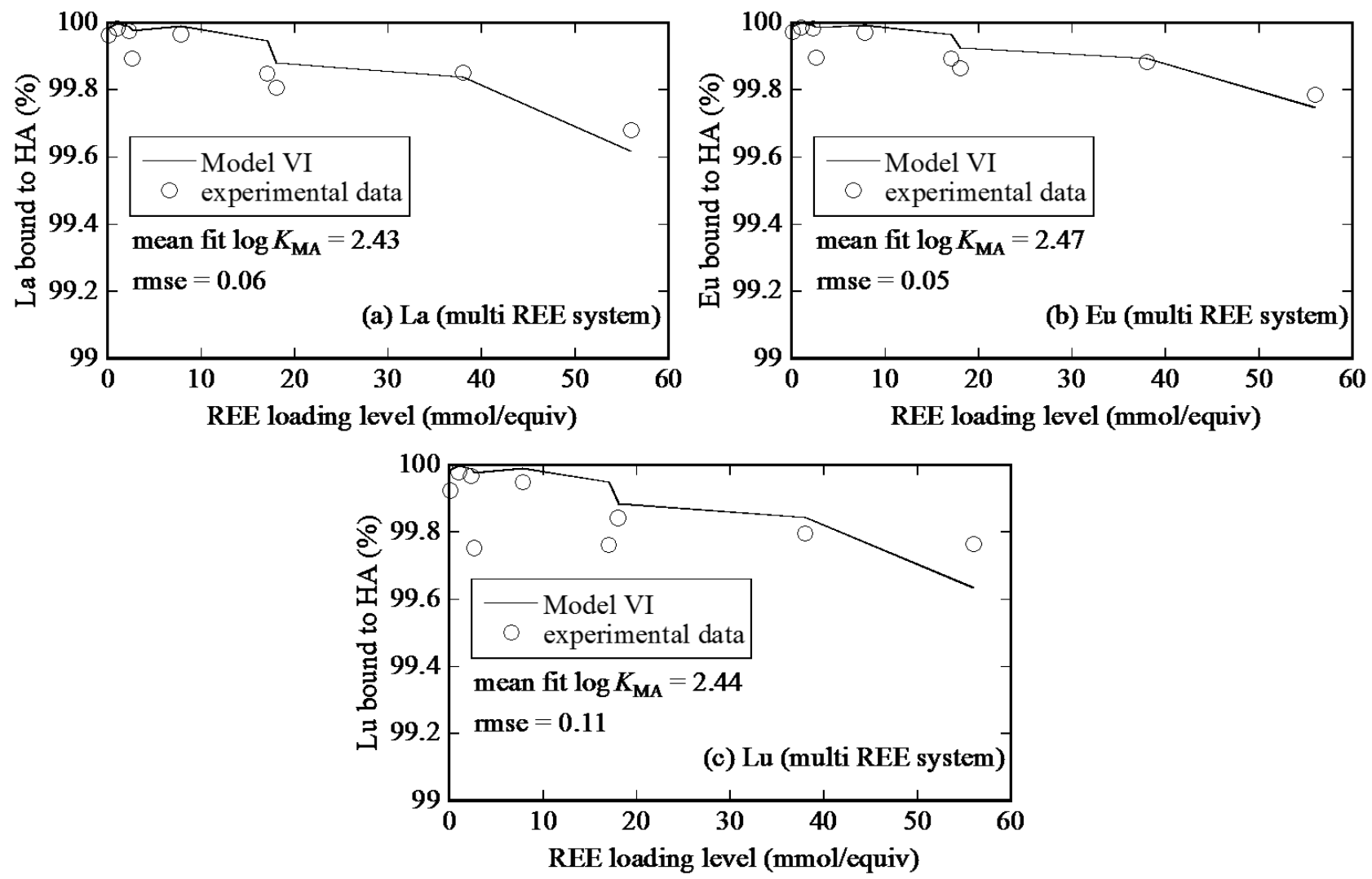

Fig. 6. Fraction of REEs bound to HA for multi-REE system using equilibrium dialysis. Open symbols are experimental values, while the solid line corresponds to values calculated by Model VI. Because pH and ionic strength are different at each data point, the solid line by Model VI is not smooth.

In other words, the results show that $K_{\mathrm{MA}}$ can vary as a function of the REE loading level. Although Model VI has parameters to reflect heterogeneities of HS, these parameters were fixed at the value reported in Sonke and Salters (2006) and Pourret et al. (2007a) to keep the consistency for comparison (Table 4). The variations in other parameters such as $Z$ (net charge of HA) are not sufficiently large to compensate the gap between the observed and calculated fractions of REE-HA complexes. To evaluate these systematic variations in REE-HA fractions at various REE loading levels, we calculated $K_{\mathrm{MA}}$ at each REE loading level (Appendices 2 and 3 ). The $K_{\mathrm{MA}}$ values determined at each REE loading level were used for the discussion on the variation in the REE pattern of $\log K_{\mathrm{MA}}$.

Since REE patterns of $\log K_{\mathrm{MA}}$ obtained here cannot be compared with those of the intrinsic stability constants $(\log K)$ for simple ligands directly due to a difference in the definition between $\log K_{\mathrm{MA}}$ and $\log K$, we calculated the $K_{\mathrm{MA}}$ values for REEs using the LFER assuming simple ligands as the binding sites. This conversion allows us to discuss the similarity of the REE pattern between HA and simple ligands. Such an approach to estimate $K_{\text {MA }}$ using the LFER for simple ligands was applied by Tang and Johannesson (2003), Sonke (2006), and Pourret et al. (2007b). $\log K$ for simple ligands used in this study were referred from Martell et al. (2003).

Since previous studies on REE-HS complexation used either Model V or VI, we also calculated $K_{\mathrm{MHA}}$ in Model $\mathrm{V}$ for REEs using the LFER for various carboxylates. $K_{\mathrm{MHA}}$ is an intrinsic equilibrium constant for Model V, which is a prototype model of Model VI (Tipping and Hurley, 1992). This procedure is essential to compare our experimental data with the theoretical and experimental values of REE-HA association based on either Model V or VI. In these models, $K_{\mathrm{MA}}$ and $K_{\mathrm{MHA}}$ for REEs were estimated by the correlation of $\log K_{\mathrm{MA}}$ (or $\log K_{\mathrm{MHA}}$ ) of $\mathrm{HA}$ and $\log K$ of simpler ligands (e.g., acetate, malonate, etc.) for various metal ions for which $K_{\mathrm{MA}}$ (or $K_{\mathrm{MHA}}$ ) is already known. Examples of the estimation were shown in Appendices 7 and 8. The relative shape of the REE pattern of estimated $\log K_{\mathrm{MA}}$ ( or $\log K_{\mathrm{MHA}}$ ) using the LFER reflects that of $\log K$ for a given ligand. Thus, we can discuss the similarity of the REE pattern of the stability constants between HA and simple ligands on the same scale. Reference metal ions used for the estimation of $K_{\mathrm{MHA}}$ and $K_{\mathrm{MA}}$ of REEs for HA by the LFER based on the stability 


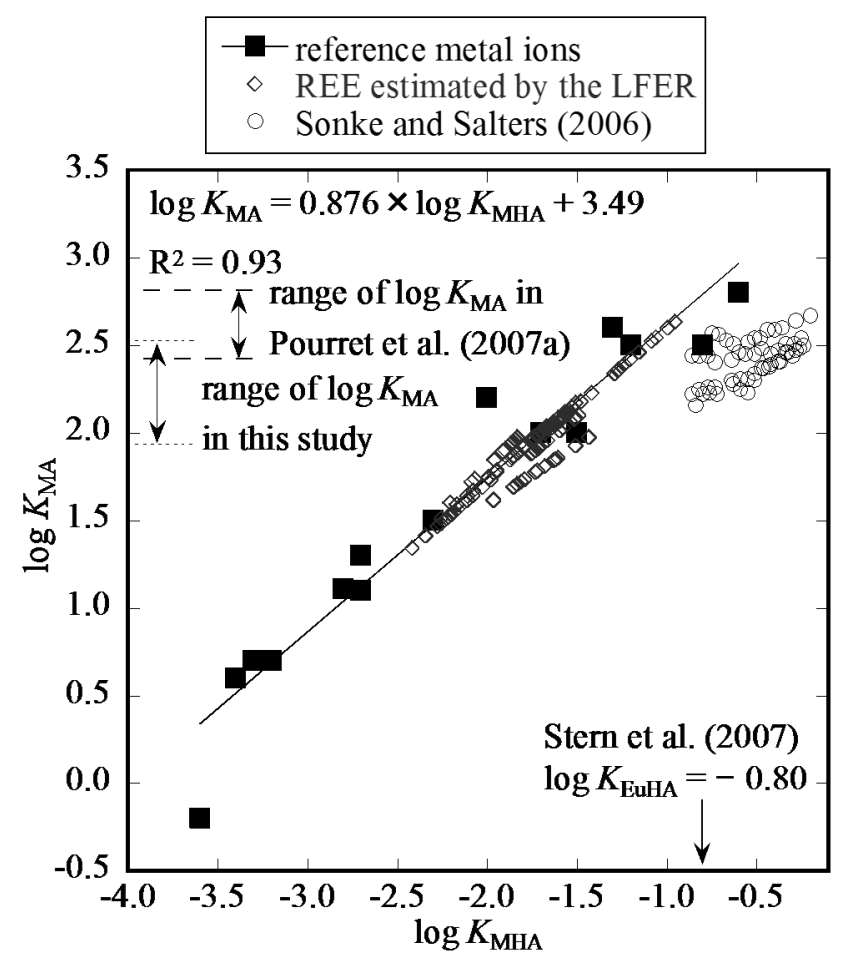

Fig. 7. The linear relationship between $\log K_{M H A}$ and $\log K_{M A}$ for HA. The solid line is the regression line for reference metal ions referred to in Tipping (1994, 1998). The region indicated by two dotted lines corresponds to the range of $\log K_{M A}$ values of this study, while the region indicated by two broken lines is the range of $\log K_{M A}$ values of Pourret et al. (2007a). The $\log K_{E u H A}$ value of Stern et al. (2007) is for the Suwannee River natural organic matter standard (SRNOM: IHSS code IRIOIN). $\log K_{M H A}$ and $\log K_{M A}$ values of $H A$ for reference metal ions and REEs are listed in Appendices 4-6.

constants for various simpler ligands are listed in Appendix 4 (Tipping, 1994, 1998). $\log K_{\mathrm{MHA}}$ and $\log K_{\mathrm{MA}}$ values are listed in Appendices 5 and 6, and the regression lines for the LFER between various simple ligands and HA are illustrated in Appendices 7 and 8. Plots of $\log K_{\mathrm{MHA}}$ vs. $\log K_{\mathrm{MA}}$ for reference metal ions clearly show a linear correlation $\left(R^{2}=0.93\right)$ (Fig. 7). This fact indicates that the REE pattern of $\log K_{\mathrm{MA}}$ shows a shape similar to that of $\log K_{\mathrm{MHA}}$. From the correlation, we can convert $K_{\mathrm{MHA}}$ values into $K_{\mathrm{MA}}$ values using an empirical relation obtained by the regression line for the reference metal ions:

$$
\log K_{\mathrm{MA}}=0.876 \times \log K_{\mathrm{MHA}}+3.49 .
$$

From this correlation, we can compare the results reported based on both Model V and VI.

Estimated values by the LFER for REEs are plotted close to the regression line, whereas data in Sonke and Salters (2006) show $\log K_{\mathrm{MA}}$ values lower than the regres- sion line (Fig. 7). This fact may be due to their experimental method, where $\left[\mathrm{REE}^{3+}\right]$ was not determined directly. Experimental $\log K_{\mathrm{MA}}$ values of our study overlap with the range for those in Sonke and Salters (2006) and are slightly lower than those in Pourret et al. (2007a). Equation (17) was used to obtain $\log K_{\mathrm{MA}}$ value from $\log K_{\mathrm{MHA}}$ data for Suwannee River natural organic matter standard (SRNOM: IHSS code 1R101N) reported in Stern et al. (2007). The estimated $\log K_{\mathrm{EuA}}$ value for SRNOM of 2.79 is slightly higher than our results.

\section{DISCUSSION}

\section{Binding sites of REEs in $H S$}

REE patterns of experimental $\log K_{\mathrm{MA}}$ are illustrated in Fig. 8. $\log K_{\mathrm{MA}}$ for the single-REE system of solvent extraction experiments are also plotted for $\mathrm{La}, \mathrm{Eu}$, and Ho (Fig. 8a). $\log K_{\mathrm{MA}}$ values for single-REE systems agree with those for the multi-REE system. It was found that experimental $\log K_{\mathrm{MA}}$ values (Fig. 8) are larger than those estimated by the LFER (Fig. 9), except for lactate. This fact indicates that speciation calculation using the $\log K_{\mathrm{MA}}$ value estimated by the LFER underestimates REE-HS complexation. It can be seen that REE patterns of $\log K_{\mathrm{MHA}}$ estimated by the LFER are quite similar to those of $\log K_{\mathrm{MA}}$ (Fig. 9).

As described previously, the similarity of REE patterns of $\log K_{\mathrm{MA}}$ between HA and reference carboxylates reflects the main binding sites of REEs in HA. REE patterns of $\log K_{\mathrm{MA}}$ estimated by the LFER for reference carboxylates are classified into two groups. The first group corresponds to simple carboxylates such as acetate and propionate. REE patterns of the first group have a broad peak around Sm and Eu (Fig. 9a). Citrate having three carboxylic groups and one hydroxy group in a unit shows a similar REE pattern with the first group. The second group corresponds to amino carboxylates such as EDTA and NTA. REE patterns of the second group show a monotonous increase with increasing of atomic number (Fig. $9 b$ ). Malonate (two carboxylic groups) and lactate (one carboxylic and one hydroxy group) also display REE patterns similar to the second group. Almost all ligands bearing carboxylic groups are also classified into these two groups.

Because the main binding sites of REEs in HSs are simple carboxylates or aminopolycarboxylates, as suggested in previous studies (Yamamoto et al., 2005; Sonke and Salters, 2006; Pourret et al., 2007a; Stern et al., 2007), REE patterns of $\log K_{\mathrm{MA}}$ for HA also can be classified into the two groups (Figs. 1 and 8). For the results of solvent extraction, REE patterns of $\log K_{\mathrm{MA}}$ are similar to that of the first group at a higher REE loading region (more than $2 \mathrm{mmol} /$ equiv). On the other hand, the REE patterns at less than $1.0 \mathrm{mmol} /$ equiv show an increase 

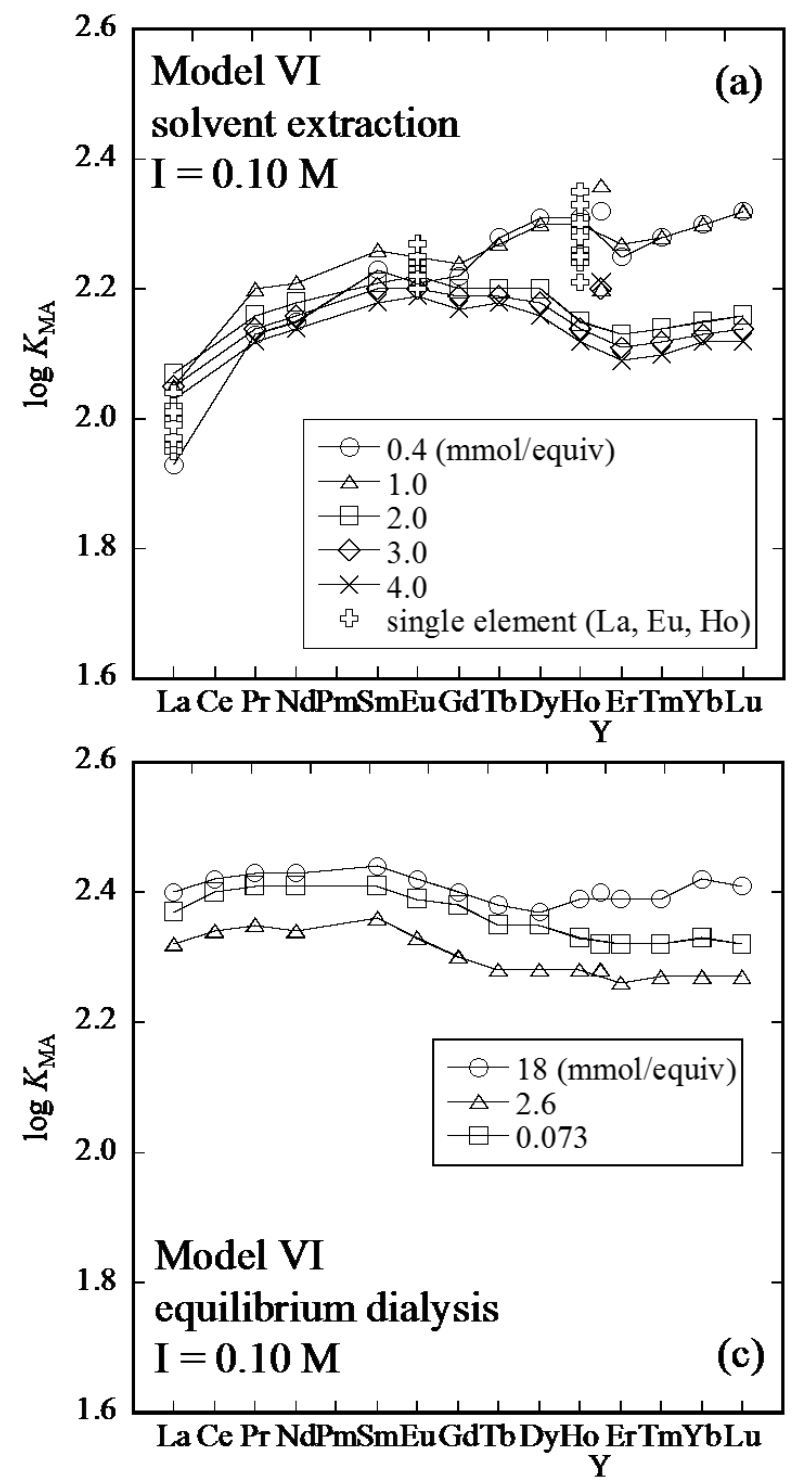

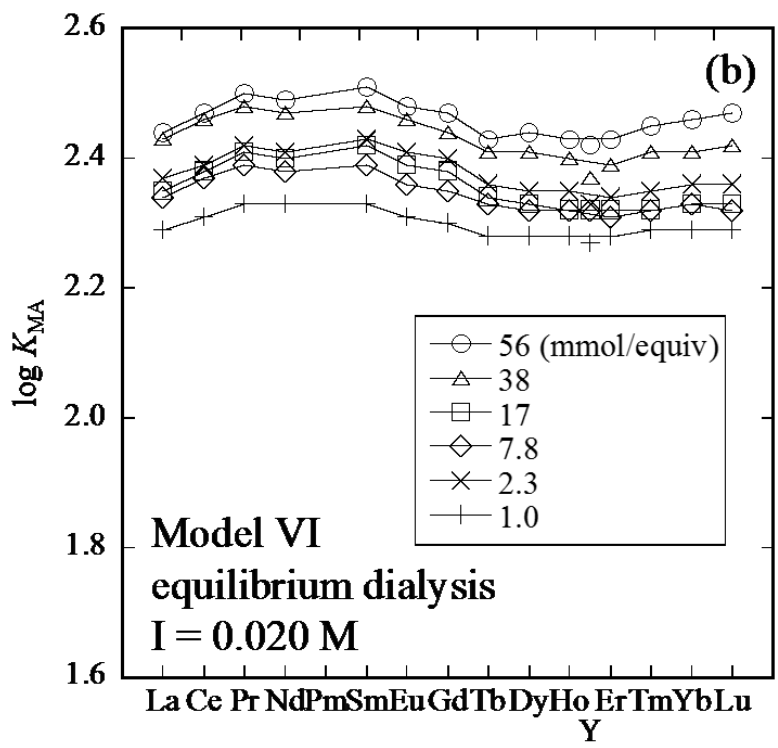

(b) 

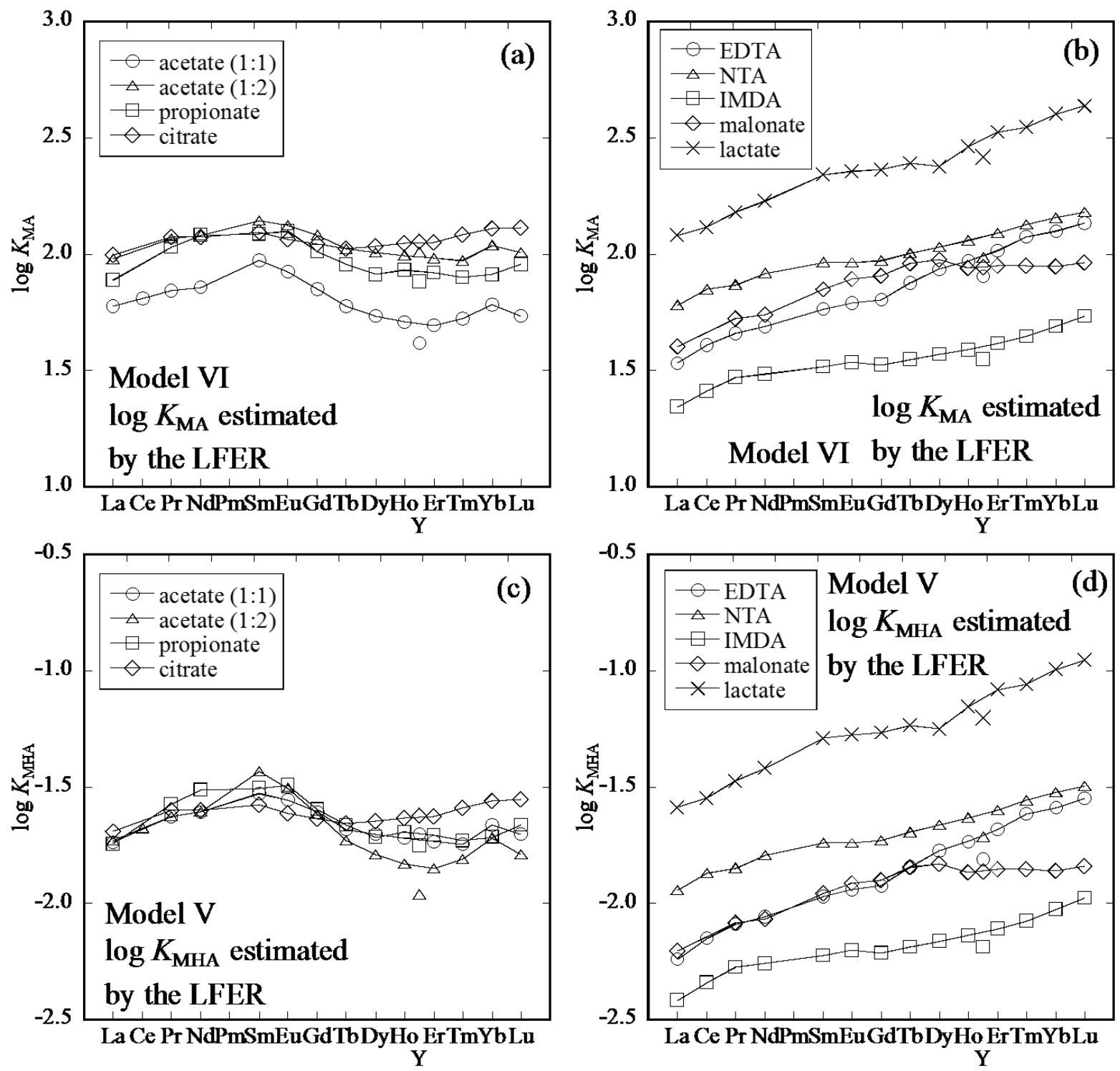

Fig. 9. Estimated REE patterns of $\log K_{M A}$ for HA. REE patterns of $\log K_{M A}$ for HA were determined by the LFER for (a) the first group; and (b) second group of carboxylates. REE patterns of $\log K_{M H A}$ estimated by the LFER for $(c)$ the first group and $(d)$ the second group.

extraction was plotted near the correlation line for estimated $K_{\mathrm{MA}}$, whereas the data for equilibrium dialysis are deviated from the line. As expected from the REE pattern of $\log K_{\mathrm{MA}}$ (Figs. 8b and c), the data for equilibrium dialysis are almost unchanged at various REE loading levels and ionic strengths.

The data for Leonardite humic acid (LHA: IHSS code 1S104H) at pH 8 and 9 in Sonke and Salters (2006) are close to those for solvent extraction at lower REE loading, whereas the data at $\mathrm{pH} 6$ and 7 are in the intermediate region between those for equilibrium dialysis and solvent extraction at a lower REE loading level (Fig. 10). The data for AHA (aldrich humic acid) in Pourret et al. (2007a) are close to those for equilibrium dialysis. Thus, a change of the binding sites of REEs in HSs with the variation in the REE loading level can be characterized by the $K_{\mathrm{LuA}} / K_{\mathrm{LaA}}$ versus $K_{\mathrm{SmA}} / K_{\mathrm{HoA}}$ plots.

In summary, it was found that the first group (simple carboxylates and citrate) comprises the major binding sites of REEs in HSs at a higher REE loading level, whereas the second group (aminopolycarboxylates, malonate, and lactate) comprises minor but more stable sites, which can be important at a lower REE loading level. Explanation for the lack of change in the REE pattern of $\log K_{\mathrm{MA}}$ determined by equilibrium dialysis with the variation in the REE loading level is described in the following section. 


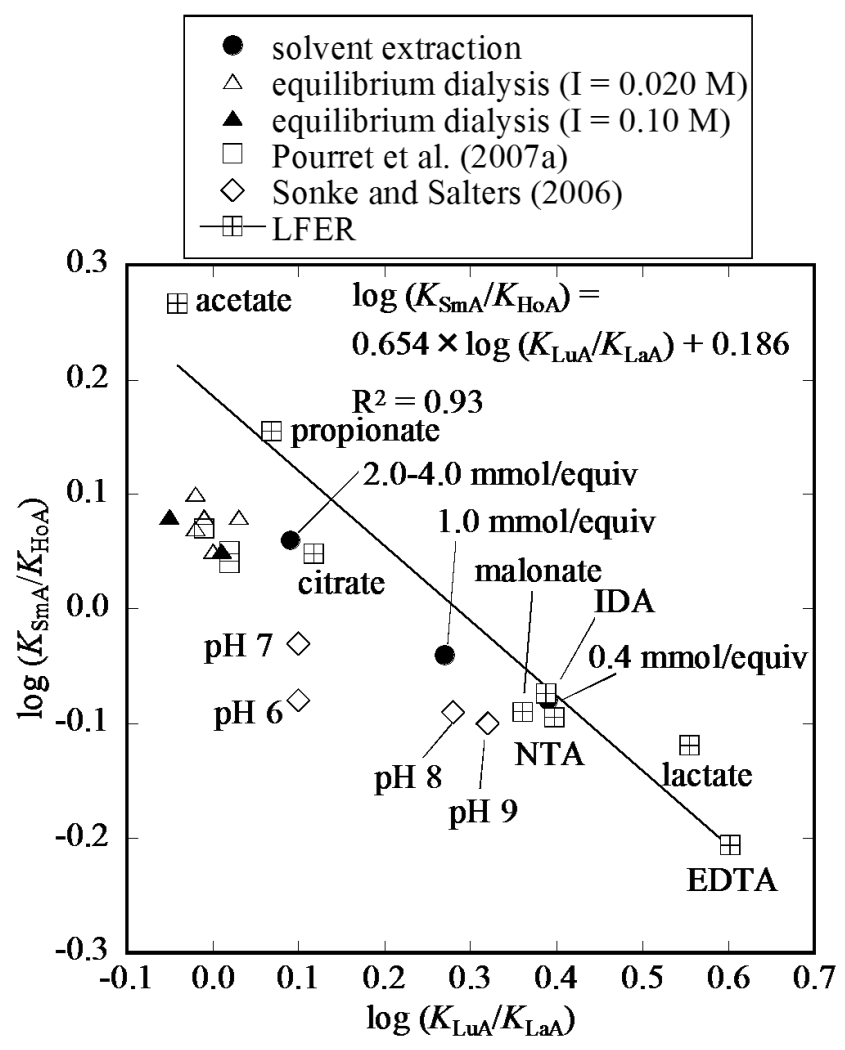

Fig. 10. Plots of $K_{L u A} / K_{L a A}$ vs. $K_{S m A} / K_{H o A}$ as an indicator of the relative shape of the REE pattern of $\log K_{M A}$. Closed circle, solvent extraction (this study); open triangle, equilibrium dialysis at $I=0.020 \mathrm{M}$ (this study); closed triangle, equilibrium dialysis at $I=0.10 \mathrm{M}$ (this study); open square, ultrafiltration (Pourret et al., 2007a); open diamond, CE-ICP-MS (Sonke and Salters, 2006); cross in square, estimated by the LFER. The solid line is the regression line for the data estimated by the LFER.

Hummel et al. (2000) also pointed out that the variation in the binding constants of $\mathrm{Eu}, \mathrm{Am}$, and $\mathrm{Cm}$ with HSs according to the metal loading can be interpreted by assuming a high concentration of lower-affinity sites and a low concentration of higher-affinity sites. They proposed a simple two-site model to explain the variation in experimental binding constants for a single element as a function of the metal loading level and that a phenolic $\mathrm{OH}$ group can be the higher-affinity site. Although the $\beta_{\mathrm{M}}$ values of all REEs with phenolic $\mathrm{OH}$ group have not been determined yet, the REE patterns of $\log \beta_{\mathrm{M}}$ of similar compounds such as catechol and naphthol do not show the steep slope as found in those of REE-HS complexes at a lower REE loading level (Martell et al., 2003). This fact suggests that the contribution of phenolic $\mathrm{OH}$ group at a lower REE loading level is not detected by our approach based on the shape of REE patterns of $\log K_{\mathrm{MA}}$ at least within the $\mathrm{pH}$ region studied here.
Factors controlling the variation in the REE pattern

In this section, differences in the experimental technique that can affect the slope of the REE pattern of $\log K_{\mathrm{MA}}$ are discussed. As described earlier, the variation in the REE pattern of $\log K_{\mathrm{MA}}$ with the REE loading level was found in the solvent extraction experiments, but not in the equilibrium dialysis. This difference in the REE pattern of $\log K_{\mathrm{MA}}$ may depend on experimental techniques to determine $\beta_{\mathrm{M}-\mathrm{HS}}$.

The concentration of major multivalent cations such as $\mathrm{Fe}^{3+}$ and $\mathrm{Al}^{3+}$ may be a possible factor controlling the slope of the REE pattern of $\log K_{\mathrm{MA}}$. Iron and $\mathrm{Al}$ originally included in HSs at a high concentrations due to their relatively large abundances and strong affinities for HSs relative to REEs. Yamamoto et al. (2009) reported that Fe exists as Fe(III) bound to carboxylic groups in SRHA. Iron hydroxides or oxides incorporated as small particles into HA samples, which can sorb REEs, were not detected using X-ray absorption fine structure (XAFS) (Yamamoto et al., 2009). It is expected that $\mathrm{Al}$ also exists as Al-HA complexes in HA. Hence, the presence of $\mathrm{Fe}$ and $\mathrm{Al}$ in $\mathrm{HA}$ can increase the metal loading level. Although $\mathrm{Fe}$ and $\mathrm{Al}$ concentrations in our samples are smaller than those in previous studies (Stookey, 1970; Kim et al., 1990) (Table 1), concentrations of $\mathrm{Fe}$ and $\mathrm{Al}$ obtained here are enough to increase the total metal loading level of HSs. Purification of HSs can remove major cations (Al, Ca, $\mathrm{Cr}, \mathrm{Mg}$, and $\mathrm{Si}$ ) from HSs to a larger degree, except for Fe (Kim et al., 1990). In addition, a portion of such major cations can be removed from HSs depending on the experimental method employed in each study. Since $\mathrm{Fe}^{3+}$ and $\mathrm{Al}^{3+}$ could be removed from HSs by EDTA due to the large stabilities of EDTA complexes with such metal ions $\left(\log K_{\mathrm{Fe} 3+\text {-EDTA }}=27.7, \log K_{\mathrm{A} 13+\text {-EDTA }}=18.9, \log K_{\mathrm{REE}-\mathrm{EDTA}}\right.$ = 17.9-22.3), experimental conditions employing EDTA as a competitive ligand in Sonke and Salters (2006) could achieve a lower metal loading level than those of the solvent extraction using DEHP, the equilibrium dialysis using citrate, and the ultrafiltration (Pourret et al., 2007a) experiments. On the other hand, a portion of such metals in HSs can also be removed by DEHP in our solvent extraction system, because the extraction coefficient of $\mathrm{Fe}^{3+}$ is larger than those of REEs $\left(\log K_{\text {ex }-\mathrm{Fe}}=3.6\right.$ and $\log K_{\text {ex-REE }}=-1.5-3.1$; Takahashi et al., 1997). Even though $\log K_{\mathrm{Fe} 3+- \text { citrate }}(13.5)$ and $\log K_{\mathrm{Al} 3+\text {-citrate }}(9.98)$ are larger than $\log K_{\text {REE-citrate }}$ (9.18-9.67; Martell et al., 2003), the degree of removal of $\mathrm{Fe}^{3+}$ and $\mathrm{Al}^{3+}$ in the equilibrium dialysis system is smaller than those of the capillary electrophoresis (Sonke and Salters, 2006) and solvent extraction systems (this study), because the stabilities of the complexes of citrate for such metal ions were smaller than those for EDTA in the capillary electrophoresis and for DEHP in the solvent extraction systems. Pourret et al. (2007a) did not employ any competitive ligands in their 

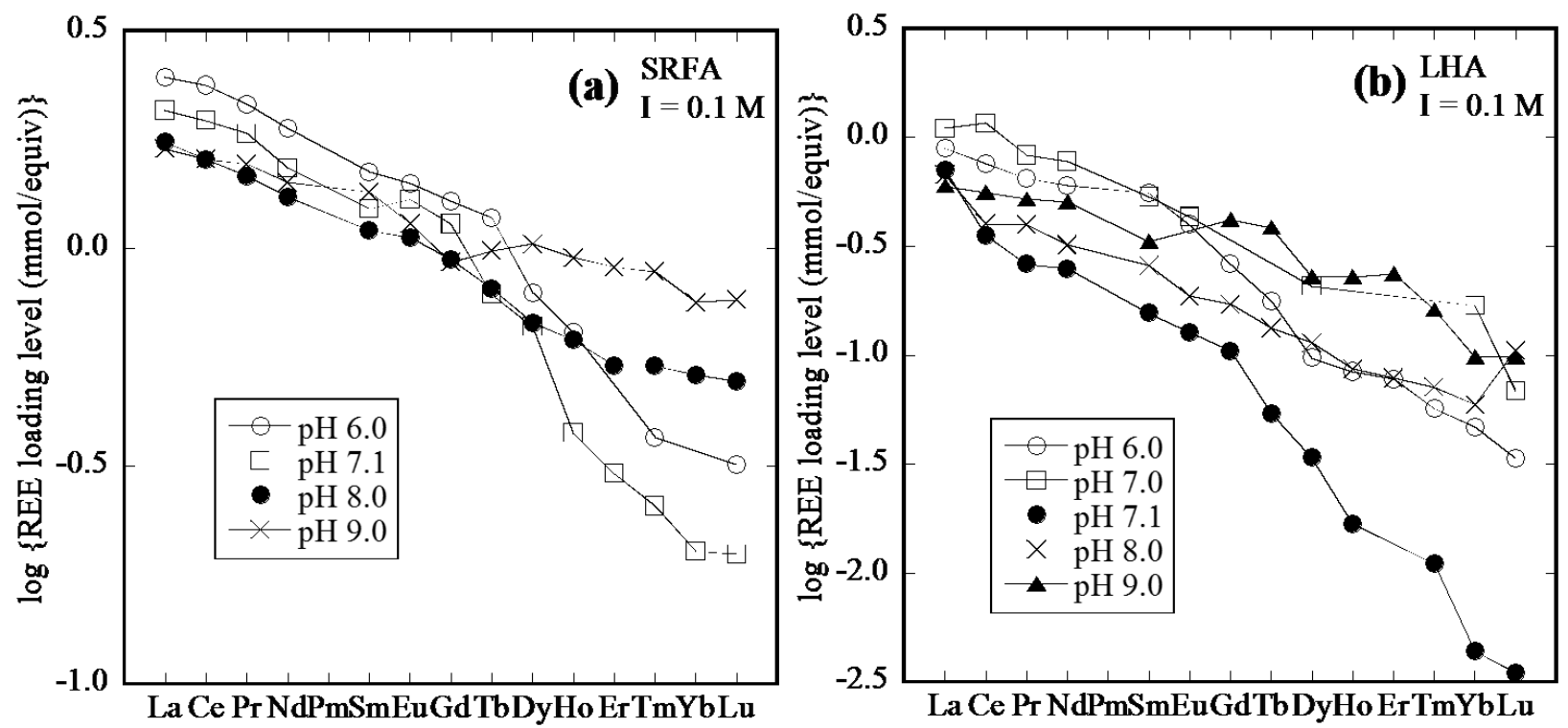

Fig. 11. REE patterns of the REE loading level in the capillary electrophoresis experiments (Sonke and Salters, 2006). (a) SRFA at ionic strength of $0.1 \mathrm{M} ;(\mathrm{b})$ LHA at ionic strength of 0.1 M. Concentrations of REE-HS complex and HSs were reported in Sonke and Salters (2006). The number of dissociated ligands was calculated using parameters reported in Ritchie and Perdue (2003).

ultrafiltration experiments.

We conducted a rough calculation of the total metal loading level including $\mathrm{Fe}^{3+}$ and $\mathrm{Al}^{3+}$. For $\mathrm{Fe}^{3+}$ and $\mathrm{Al}^{3+}$, we assume that a single metal ion is bound to a single site in HSs as is similar to REEs. Fractions of $\mathrm{Fe}^{3+}$ and $\mathrm{Al}^{3+}$ bound to HSs were calculated using Model VI (Tipping, 1998). The total metal loading levels range from 0.4 to $15 \mathrm{mmol} /$ equiv for solvent extraction and from 5 to 60 $\mathrm{mmol} /$ equiv for equilibrium dialysis, respectively. By considering the contributions of $\mathrm{Fe}^{3+}$ and $\mathrm{Al}^{3+}$, the inflection point of $\log \beta_{\mathrm{M}-\mathrm{HS}}$ changes from 1.5 to $2.0-3.5 \mathrm{mmol} / \mathrm{equiv}$ for solvent extraction, from 15 to $20 \mathrm{mmol} /$ equiv for equilibrium dialysis at an ionic strength of $0.020 \mathrm{M}$, and from 2.6 to $7.0 \mathrm{mmol} /$ equiv for equilibrium dialysis at an ionic strength of $0.10 \mathrm{M}$.

The range of the metal loading level of Pourret et al. (2007a) is slightly higher (43-240 mmol/equiv) than the range of the REE loading level (40-230 $\mathrm{mmol} /$ equiv) due to their prior purification of HS. Since concentrations of $\mathrm{Fe}$ and $\mathrm{Al}$ in LHA employed in Sonke and Salters (2006) were not determined, concentrations of $\mathrm{Fe}$ and $\mathrm{Al}$ in LHA are assumed to be similar to that of AHA. Thus, the metal loading level of Sonke and Salters (2006) is estimated to range from 0.1 to $34 \mathrm{mmol} /$ equiv.

Based on the rough estimation of the metal loading level, it was confirmed that the slope of the REE pattern of $\log K_{\mathrm{MA}}$ is steeper at a lower metal loading region (0.4$3.5 \mathrm{mmol} /$ equiv). On the other hand, the relative shape of the REE pattern of $\log K_{\mathrm{MA}}$ at a higher metal loading region (3.5-240 mmol/equiv) is similar to those of simple carboxylates and remains almost unchanged as the metal loading level increases. Therefore, the contributions of $\mathrm{Fe}^{3+}$ and $\mathrm{Al}^{3+}$ may be a plausible reason for the steep slope in the REE pattern of $\log K_{\mathrm{MA}}$ observed in the capillary electrophoresis in Sonke and Salters (2006) and in our solvent extraction experiments, but not in the equilibrium dialysis in our experiments and ultrafiltration experiments in Pourret et al. (2007a). Since concentrations of $\mathrm{Fe}^{3+}$ and $\mathrm{Al}^{3+}$ in the experimental system were not reported simultaneously in previous studies on the stability constants of REE-HS complexes, more quantitative discussion on the effects of $\mathrm{Fe}^{3+}$ and $\mathrm{Al}^{3+}$ on the complexation of REE with HSs is difficult. Determination of concentrations of major multivalent cations such as $\mathrm{Fe}^{3+}$ and $\mathrm{Al}^{3+}$ is necessary for the precise estimation of the metal loading level and to understand the variation in $\log K_{\mathrm{MA}}$ at various metal loading levels.

If the REE pattern of $\log K_{\mathrm{MA}}$ is obtained by the determination of $\log K_{\mathrm{MA}}$ for each REE by independent experiments, the variation in the REE loading level in the experiments is another factor controlling the slope of the REE pattern of $\log K_{\mathrm{MA}}$. Sonke and Salters (2006) determined $\beta_{\mathrm{M}-\mathrm{HS}}$ of all REE ions independently by capillary electrophoresis using EDTA as a competitive ligand, where $\beta_{\mathrm{M}-\mathrm{HS}}$ was obtained separately for each REE. The REE loading level can be variable among different REE as a result of competition between HSs and EDTA in Sonke and Salters (2006). In other words, the concentration of free metal ions in the system is much smaller for heavy REEs (HREEs) than for light REEs (LREEs) due 
to much larger stabilities of HREE-EDTA complexes than those of LREE-EDTA. Even though $\beta_{\mathrm{M}-\mathrm{HS}}$ of all REEs were determined at identical $\mathrm{pH}$, ionic strength, and concentrations of HSs and REEs, the REE loading level in the experiments of Sonke and Salters (2006) decreased from $\mathrm{La}$ to $\mathrm{Lu}$ due to the larger $\beta_{\mathrm{M}}$-EDTA values for HREEs. Figure 11 shows REE patterns of the REE loading levels in Sonke and Salters (2006), where $\beta_{\mathrm{M}-\mathrm{HS}}$ of each REE was determined independently. The REE loading level was calculated from the combination of concentrations of HSs and REE-HS complexes reported in Sonke and Salters (2006), and the degree of dissociation of HSs was calculated based on Ritchie and Perdue (2003). The REE loading level decreased monotonously with the increase in the atomic number within the ranges of 2.5 to $0.20 \mathrm{mmol} /$ equiv for SRFA and 1.2 to $0.0035 \mathrm{mmol} /$ equiv for LHA. These facts suggest that the steep slope of $\log \beta_{\mathrm{M}-\mathrm{HS}}$ found in Sonke and Salters (2006) was caused by the decrease in the REE loading level from $\mathrm{La}$ to $\mathrm{Lu}$ in REE series in their experimental systems. Thus, the metal loading level is an important parameter, especially when $\beta_{\mathrm{M}-\mathrm{HS}}$ for each REE is determined independently.

\section{Relationship between slope of REE pattern of $\log K$ and denticity}

Spectroscopic results obtained by near-edge X-ray absorption fine structure (NEXAFS) at $\mathrm{C} \mathrm{K}$-edge for $\mathrm{Eu}^{3+}$ HS aggregation at a much higher REE loading level (6.3 $\mathrm{mM} \mathrm{Eu}{ }^{3+}, 200 \mathrm{mg} / \mathrm{dm}^{3} \mathrm{HS}$ ) are similar to that of Eu-PAA (polyacrylic acid) complex (Plaschke et al., 2004). This suggested that the binding sites of $\mathrm{Eu}^{3+}$-HA complexes are monocarboxylic groups at such a high REE loading level.

On the other hand, a study using the fluorescence lifetime of $\mathrm{Eu}^{3+}$ reported that $\mathrm{Eu}^{3+}$-HS complexation (mixture of SRHA and SRFA) at $\mathrm{pH} 3.5$ and at a lower REE loading level $\left(10^{-2}-10^{-7} \mathrm{M} \mathrm{Eu}^{3+}, 30 \mathrm{mg} / \mathrm{dm}^{3} \mathrm{HS}\right)$ is dominated by tetradentate complexes (Thomason et al., 1996). According to the study, a decrease in the REE loading level leads to an increase in the denticity of HS to $\mathrm{Eu}^{3+}$. Denticity is defined as the number of donor groups from a given ligand binding to the same metal ion. For example, the denticities of REE-citrate, REE-NTA, and REEEDTA complexes are three, four, and six, respectively. Generally, the $K_{\mathrm{Lu}} / K_{\mathrm{La}}$ ratio (which is the slope of REE pattern) increases with an increase in the denticity of REEligand complexes (Fig. 12) (Smith and Martell, 1987), where $K_{\mathrm{Lu}}$ and $K_{\mathrm{La}}$ are the intrinsic stability constants of $\mathrm{Lu}$ and $\mathrm{La}$ for a given ligand. Thus, it is possible that the increase in the denticity of HSs to $\mathrm{Eu}^{3+}$ with the decrease in the REE loading level, or the increase in the contribution of minor chelating sites to HS complexation, can be reflected in the slope of the REE pattern of $\log K_{\mathrm{MA}}$.

In the case of experimental intrinsic stability constants

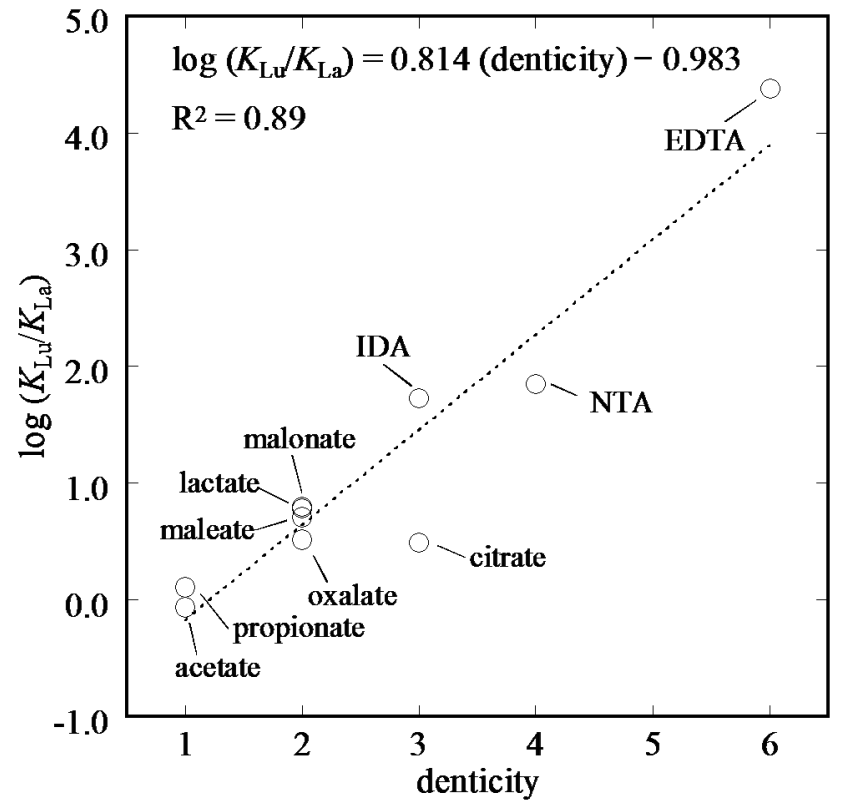

Fig. 12. Relationship between slope of REE patterns of the intrinsic stability constants for various carboxylates and denticity. Denticity of 1 , acetate and propionate; 2 , malonate, maleate, lactate, and oxalate; 3 , citrate and iminodiacetate (IDA); 4, NTA; and 6, EDTA.

of REEs for HSs $\left(K_{\mathrm{MA}}\right)$, the $K_{\mathrm{LuA}} / K_{\mathrm{LaA}}$ ratio increased with the decrease in the metal loading level. This fact indicates that the steep slope of the REE pattern of $\log K_{\mathrm{MA}}$ requires chelation of the binding sites of REEs in HSs, and that the chelating sites are likely to be the main binding sites of REEs in HSs at a lower metal loading region. Thus, the variation in the REE pattern of $\log K_{\mathrm{MA}}$ with the metal loading level is consistent with the results of previous spectroscopic studies.

\section{CONCLUSIONS}

The $\beta_{\mathrm{M}-\mathrm{HS}}$ values of SRHA for all REEs (except for Pm) were determined simultaneously at various REE loading levels by solvent extraction and equilibrium dialysis methods. $\beta_{\mathrm{M}-\mathrm{HS}}$ decreases with an increase in the REE loading level in both methods. The mean fit for $K_{\mathrm{MA}}$ with the variation in the REE loading level is not good for HREEs in the solvent extraction experiments, reflecting the decrease in $\log K_{\mathrm{MA}}$ with the increase in the REE loading level. Changes in the relative shape of the REE patterns with the variation in the REE loading level were found in the results of solvent extraction, but not in those of equilibrium dialysis. The different results between these two experimental methods could be explained by the degree of removal of major cations such as $\mathrm{Fe}^{3+}$ and $\mathrm{Al}^{3+}$ from HSs in the experimental systems. The main binding 
sites of REEs in HA at a higher metal loading level (3.5$240 \mathrm{mmol} / \mathrm{equiv}$ ) are estimated to be simple carboxylates inferred from the similarity of the REE patterns of $\log K_{\mathrm{MA}}$ to those of simple carboxylates. The contribution of chelating sites to the complexation with HSs increases at a lower metal loading level (0.4-3.5 mmol/equiv). As a result, it is strongly suggested that REE pattern of stability constants of REE-HS complexes shows an increase with the increase in the atomic number at a low metal loading level, whereas the REE pattern has a peak around middle REE region at a high metal loading level. This finding may be closely related to the REE fractionation in natural terrestrial waters caused by the complexation with HSs. In particular, the fractionation related to the complexation with HSs may be affected by the metal loading level, a key parameter to understand comparatively the complexation of each REE with HSs.

Acknowledgments-This research was supported by a Grantin-Aid for Scientific Research from the Japan Society for the Promotion of Science. The first author is indebted to the Japan Society for the Promotion of Science for a research fellowship. We thank Dr. I. Kawabe and an anonymous reviewer for their helpful and constructive comments on the manuscript.

\section{REFERENCES}

Baes, C. F., Jr. (1962) The extraction of metallic species by dialkylphosphoric acids. J. Inorg. Nucl. Chem. 24, 707-720.

Bau, M. and Dulski, P. (1996) Anthropogenic origin of positive gadolinium anomalies in river waters. Earth Plant. Sci. Lett. 143, 245-255.

Bertram, C. J. and Elderfield, H. (1993) The geochemical balance of the rare earth elements and neodymium isotopes in the oceans. Geochim. Cosmochim. Acta 57, 1957-1986.

Bidoglio, G., Grenthe, I., Robouch, P. and Omenetto, N. (1991) Complexation of Eu and $\mathrm{Tb}$ with fulvic acids as studied by time-resolved laser-induced fluorescence. Talanta 38, 9991008 .

Byrne, R. H. and Kim, K. H. (1990) Rare earth element scavenging in seawater. Geochim. Cosmochim. Acta 54, 26452656.

Caceci, M. S. (1985) The interaction of humic acid with europium(III). Complexation strength as a function of load and pH. Radiochim. Acta 39, 51-56.

Dierckx, A., Maes, A. and Vancluysen, J. (1994) Mixed complex formation of $\mathrm{Eu}^{3+}$ with humic acid and a competing ligand. Radiochim. Acta 66/67, 149-156.

Dong, W. M., Zhang, H. X., Huang, M. and Tao, Z. Y. (2002) Use of the ion exchange method for the determination of stability constants of trivalent metal complexes with humic and fulvic acids-Part $\mathrm{I}$ : $\mathrm{Eu}^{3+}$ and $\mathrm{Am}^{3+}$ complexes in weakly acidic conditions. Appl. Radiat. Isot. 56, 959-965.

Gaillardet, J., Dupre, B., Allegre, C. J. and Négrel, P. (1997) Chemical and physical denudation in the Amazon River Basin. Chem. Geol. 142, 141-173.

Gaillardet, J., Viers, J. and Dupre, B. (2003) Trace Elements in River Waters, Treatise of Geochemistry. Pergamon, Oxford, pp. 225-272.

Glaus, M. A., Hummel, W. and VanLoon, L. R. (1995a) Equilibrium dialysis-ligand exchange: adaptation of the method for determination of conditional stability constants of radionuclide-fulvic acid complexes. Anal. Chim. Acta 303, 321-331.

Glaus, M. A., Hummel, W. and VanLoon, L. R. (1995b) Stability of mixed-ligand complexes of metal ions with humic substances and low molecular weight ligands. Environ. Sci. Technol. 29, 2150-2153.

Glaus, M. A., Hummel, W. and VanLoon, L. R. (2000) Trace metal-humate interactions. I. Experimental determination of conditional stability constants. Appl. Geochem. 15, 953973.

Henderson, P. (1984) Rare Earth Element Geochemistry. Elsevier, Amsterdam.

Hummel, W., Glaus, M. and VanLoon, L. R. (2000) Trace metalhumate interactions. II. The "conservative roof" model and its application. Appl. Geochem. 15, 975-1001.

Ingri, J., Widerlund, A., Land, M., Gustafsson, Ö., Andersson, P. and Öhlander, B. (2000) Temporal variations in the fractionation of the rare earth elements in a boreal river; the role of colloidal particles. Chem. Geol. 166, 23-45.

Johannesson, K. H., Farnham, I. M., Guo, C. X. and Stetzenbach, K. J. (1999) Rare earth element fractionation and concentration variations along a groundwater flow path within a shallow, basin-fill aquifer, southern Nevada, USA. Geochim. Cosmochim. Acta 63, 2697-2708.

Johannesson, K. H., Tang, J. W., Daniels, J. M., Bounds, W. J. and Burdige, D. J. (2004) Rare earth element concentrations and speciation in organic-rich blackwaters of the Great Dismal Swamp, Virginia, USA. Chem. Geol. 209, 271-294.

Kim, J. I., Buckau, G., Li, G. H., Duschner, H. and Psarros, N. (1990) Characterization of humic and fulvic acids from Gorleben groundwater. Fresenius J. Anal. Chem. 338, 245252.

Kubota, T., Tochiyama, O., Tanaka, K. and Niibori, Y. (2002) Complex formation of $\mathrm{Eu}(\mathrm{III})$ with humic acid and polyacrylic acid. Radiochim. Acta 90, 569-574.

Lead, J. R., Hamilton-Taylor, J., Peters, A., Reiner, S. and Tipping, E. (1998) Europium binding by fulvic acids. Anal. Chim. Acta 369, 171-180.

Martell, A. E., Smith, R. M. and Motekaitis, R. J. (2003) NIST Critically Selected Stability Constants of Metal Complexes, Ver. 7.

Moulin, V., Tits, J., Moulin, C., Decambox, P., Mauchien, P. and Deruty, O. (1992) Complexation behavior of humic substances towards actinides and lanthanides studied by time-resolved laser-induced spectrofluorometry. Radiochim. Acta 58/59, 121-128.

Nelson, B. J., Wood, S. A. and Osiensky, J. L. (2003) Partitioning of REE between solution and particulate matter in natural waters: a filtration study. J. Sol. Sta. Chem. 171, 51-56.

Nozaki, Y., Lerche, D., Alibo, D. S. and Snidvongs, A. (2000) The estuarine geochemistry of rare earth elements and indium in the Chao Phraya River, Thailand. Geochim. Cosmochim. Acta 64, 3983-3994.

Peppard, D. F., Mason, G. W., Maier, J. L. and Driscoll, W. J. (1957) Fractional extraction of the lanthanides as their dialkyl orthophosphates. J. Inorg. Nucl. Chem. 4, 334-343. 
Plaschke, M., Rothe, J., Denecke, M. A. and Fanghänel, T. (2004) Soft X-ray spectromicroscopy of humic acid europium(III) complexation by comparison to model substances. J. Electron. Spectrosc. Relat. Phenom. 135, 5362.

Pokrovsky, O. S. and Schott, J. (2002) Iron colloids/organic matter associated transport of major and trace elements in small boreal rivers and their estuaries (NW Russia). Chem. Geol. 190, 141-179.

Pourret, O., Davranche, M., Gruau, G. and Dia, A. (2007a) Rare earth elements complexation with humic acid. Chem. Geol. 243, 128-141.

Pourret, O., Davranche, M., Gruau, G. and Dia, A. (2007b) Organic complexation of rare earth elements in natural waters: Evaluating model calculations from ultrafiltration data. Geochim. Cosmochim. Acta 71, 2718-2735.

Reid, P. M., Wilkinson, A. E., Tipping, E. and Jones, M. N. (1990) Determination of molecular weights of humic substances by analytical (UV scanning) ultracentrifugation. Geochim. Cosmochim. Acta 54, 131-138.

Ritchie, J. D. and Perdue, E. M. (2003) Proton-binding study of standard and reference fulvic acids, humic acids, and natural organic matter. Geochim. Cosmochim. Acta 67, 8596.

Smith, R. M. and Martell, A. E. (1987) Critical stability constants, enthalpies and entropies for the formation of metal complexes of aminopolycarboxylic acid and carboxylic acid. Sci. Tot. Environ. 64, 125-147.

Sonke, J. E. and Salters, V. J. M. (2006) Lanthanide-humic substances complexation. I. Experimental evidence for a lanthanide contraction effect. Geochim. Cosmochim. Acta 70, 1495-1506.

Sonke, R. M. (2006) Lanthanide-humic substances complexation. II. calibration of humic ion-bonding Model V. Environ. Sci. Technol. 40, 7481-7487.

Stary, J. (1966) Separation of transplutonium elements. Talanta 13, 421-437.

Stern, J. C., Sonke, J. E. and Salters, V. J. M. (2007) A capillary electrophoresis-ICP-MS study of rare earth element complexation by humic acids. Chem. Geol. 246, 170-180.

Stookey, L. L. (1970) Ferrozine-a new spectrophotometric reagent for iron. Anal. Chem. 42, 779-781.

Stumm, W. (1992) Chemistry of the Solid-Water Interface. Wiley-Interscience, New York.

Stumm, W. and Morgan, J. J. (1996) Aquatic Chemistry. WileyInterscience, New York.

Takahashi, Y., Minai, Y., Meguro, Y., Toyoda, S. and Tominaga, T. (1994) Ionic strength and $\mathrm{pH}$ dependence of binding constants of Am(III)- and Eu(III)-humate. J. Radioanal. Nucl. Chem. 186, 129-141.

Takahashi, Y., Minai, Y., Ambe, S., Makide, Y., Ambe, F. and Tominaga, T. (1997) Simultaneous determination of stability constants of humate complexes with various metal ions using multitracer technique. Sci. Tot. Environ. 198, 61-71.

Takahashi, Y., Châtellier, X., Hattori, K. H., Kato, K. and Fortin, D. (2005) Adsorption of rare earth elements onto bacterial cell walls and its implication for REE sorption onto natural microbial mats. Chem. Geol. 219, 53-67.

Tang, J. and Johannesson, K. (2003) Speciation of rare earth elements in natural terrestrial waters: Assessing the role of dissolved organic matter from the modeling approach. Geochim. Cosmochim. Acta 67, 2321-2339.

Tang, J. and Johannesson, K. (2005) Adsorption of rare earth elements onto Carrizo sand: Experimental investigations and modeling with surface complexation. Geochim. Cosmochim. Acta 69, 5247-5261.

Tanizaki, Y., Shimokawa, T. and Nakamura, M. (1992) Physicochemical speciation of trace Elements in river waters by size fractionation. Environ. Sci. Technol. 26, 1433-1444.

Thomason, J. W., Susetyo, W. and Carreira, L. A. (1996) Fluorescence studies of metal humic complexes with the use of lanthanide ion probe spectroscopy. Appl. Spectrosc. 50, 401408.

Tipping, E. (1994) A chemical equilibrium model and computer code for waters, sediments, and soils incorporating a discrete site/electrostatic model of ion-binding by humic substances. Comp. Geosci. 20, 973-1023.

Tipping, E. (1998) Humic ion-binding Model VI: An improved description of the interactions of proton and metal ions with humic substances. Aquat. Geochem. 4, 3-48.

Tipping, E. (2002) Cation Binding by Humic Substances. Cambridge University Press, Cambridge.

Tipping, E. and Hurley, M. A. (1992) A unifying model of cation binding by humic substances. Geochim. Cosmochim. Acta 56, 3627-3641.

Tochiyama, O., Niibori, Y., Tanaka, K., Kubota, T., Yoshino, H., Kirishima, A. and Setiawan, B. (2004) Modeling of the complex formation of metal ions with humic acids. Radiochim. Acta 92, 559-565.

Torres, R. A. and Choppin, G. R. (1984) Europium(III) and americium(III) stability constants with humic acid. Radiochim. Acta 35, 143-148.

Yamamoto, Y., Takahashi, Y. and Shimizu, H. (2005) Systematics of stability constants of fulvate complexes with rare earth ions. Chem. Lett. 34, 880-881.

Yamamoto, Y., Takahashi, Y. and Shimizu, H. (2009) Speciation of iron in humic substances by X-ray absorption fine structure and its effect on the complexation between humic substances and trace metal ions. Chem. Lett. 38, 278-279.

\section{APPEndix 1. Calculation of $K_{\text {Ma }}$ BY Model VI (TIPPING, 1998)}

In this model, 8 monodentate, 24 bidentate, and 48 tridentate sites are assumed to form complexes with metal ions. Bidentate and tridentate sites are formed by the combination of the monodentate sites. Monodentate sites have specific proton dissociation constants $\left(K_{\mathrm{H}}\right)$ and stability constants of metal ions $\left(K_{\mathrm{M}}\right)$.

$$
\begin{aligned}
& {\left[\mathrm{HA}_{i}\right] \leftrightarrow\left[\mathrm{H}^{+}\right]+\left[\mathrm{A}_{i}^{-}\right]} \\
& K_{\mathrm{Hi}}=\left[\mathrm{H}^{+}\right]\left[\mathrm{A}_{i}^{-}\right] /\left[\mathrm{HA}_{i}\right] \\
& \left.\left[\mathrm{A}_{i}^{-}\right]+\left[\mathrm{M}^{z+}\right] \leftrightarrow\left[\mathrm{MA}_{i}^{(z-1)}\right)^{+}\right] \\
& K_{\mathrm{Mi}}=\left[\mathrm{MA}_{i}^{(z-1)+}\right] /\left[\mathrm{A}_{i}^{-}\right]\left[\mathrm{M}^{z+}\right]
\end{aligned}
$$


$(i=1-8)$. In Model VI, $K_{\mathrm{Mi}}$ is defined as a function of $K_{\mathrm{MA}}$ :

$\log K_{\mathrm{Mi}}=\log K_{\mathrm{MA}}+(2 i-5) / 6 \cdot \Delta L K_{1}(i=1-4)$,

$\log K_{\mathrm{Mi}}=3.39 \cdot \log K_{\mathrm{MA}}+(2 i-13) / 6 \cdot \Delta L K_{1}-1.15$

$$
(\mathrm{i}=5-8) \text {, }
$$

where $\Delta L K_{1}$ is the distribution term that modifies $\log K_{\mathrm{MA}}$. Considering the effect of electrostatic interaction due to the net charge $(Z)$ of humic molecule, the intrinsic proton dissociation and stability constants are modified as below:

$$
K_{\mathrm{Hi}}(Z)=K_{\mathrm{Hi}} \exp (2 \omega Z)
$$

$$
K_{\mathrm{Mi}}(Z)=K_{\mathrm{Mi}} \exp (-2 \omega z Z) .
$$

Here, $z$ is the charge on the cation, $\omega$ the electrostatic interaction factor given in terms of ionic strength $I$ and $P$ as an adjustable parameter for optimization:

$$
\omega=P \log I .
$$

Therefore, $K_{\mathrm{Mi}}(\mathrm{Z})$ is corresponding to $\beta_{\mathrm{M}-\mathrm{HS}}$ of a monodentate site. Intrinsic proton dissociation and stability constants of bidentate and tridentate sites are defined as functions of those for monodentate sites constituting the multidentate sites. For details of Model VI, refer to Tipping (1998).

Appendix 2. $\log K_{M A}$ of SRHA for solvent extraction

\begin{tabular}{lccccccc}
\hline$I(\mathrm{M})$ & 0.10 & 0.10 & 0.10 & 0.10 & 0.10 & & \\
$\mathrm{REE}$ loading* & 0.4 & 1.0 & 2.0 & 3.0 & 4.0 & mean fit & rmse \\
\hline $\mathrm{Y}$ & 2.32 & 2.36 & 2.20 & 2.20 & 2.21 & 2.22 & 0.06 \\
$\mathrm{La}$ & 1.93 & 2.05 & 2.07 & 2.05 & 2.03 & 2.02 & 1.12 \\
$\mathrm{Ce}$ & & & & & & & \\
$\mathrm{Pr}$ & 2.13 & 2.20 & 2.16 & 2.14 & 2.12 & 2.14 & 0.11 \\
$\mathrm{Nd}$ & 2.15 & 2.21 & 2.18 & 2.16 & 2.14 & 2.16 & 0.08 \\
$\mathrm{Sm}$ & 2.23 & 2.26 & 2.21 & 2.20 & 2.18 & 2.20 & 0.05 \\
$\mathrm{Eu}$ & 2.21 & 2.25 & 2.22 & 2.20 & 2.19 & 2.21 & 0.03 \\
$\mathrm{Gd}$ & 2.22 & 2.24 & 2.20 & 2.19 & 2.17 & 2.19 & 0.05 \\
$\mathrm{~Tb}$ & 2.28 & 2.27 & 2.20 & 2.19 & 2.18 & 2.20 & 0.06 \\
$\mathrm{Dy}$ & 2.31 & 2.30 & 2.20 & 2.18 & 2.16 & 2.19 & 0.09 \\
$\mathrm{Ho}$ & 2.31 & 2.30 & 2.15 & 2.14 & 2.12 & 2.14 & 0.18 \\
$\mathrm{Er}$ & 2.25 & 2.27 & 2.13 & 2.11 & 2.09 & 2.12 & 0.24 \\
$\mathrm{Tm}$ & 2.28 & 2.28 & 2.14 & 2.12 & 2.10 & 2.13 & 0.21 \\
$\mathrm{Yb}$ & 2.30 & 2.30 & 2.15 & 2.13 & 2.12 & 2.14 & 0.18 \\
$\mathrm{Lu}$ & 2.32 & 2.32 & 2.16 & 2.14 & 2.12 & 2.15 & 0.17 \\
\hline
\end{tabular}

*Unit is mmollequiv.

Appendix 3. $\log K_{M A}$ of SRHA for equilibrium dialysis

\begin{tabular}{lccccccccccc}
\hline$I(\mathrm{M})$ & 0.020 & 0.020 & 0.020 & 0.020 & 0.020 & 0.020 & 0.10 & 0.10 & 0.10 & & \\
REE loading* & 56 & 38 & 17 & 7.8 & 2.3 & 1.0 & 18 & 2.6 & 0.073 & mean fit & rmse \\
\hline $\mathrm{Y}$ & 2.42 & 2.37 & 2.32 & 2.32 & 2.33 & 2.27 & 2.40 & 2.28 & 2.32 & 2.40 & 0.10 \\
$\mathrm{La}$ & 2.44 & 2.43 & 2.35 & 2.34 & 2.37 & 2.29 & 2.40 & 2.32 & 2.37 & 2.43 & 0.06 \\
$\mathrm{Ce}$ & 2.47 & 2.46 & 2.38 & 2.37 & 2.39 & 2.31 & 2.43 & 2.35 & 2.41 & 2.46 & 0.04 \\
$\mathrm{Pr}$ & 2.50 & 2.48 & 2.41 & 2.39 & 2.42 & 2.33 & 2.44 & 2.36 & 2.42 & 2.48 & 0.03 \\
$\mathrm{Nd}$ & 2.49 & 2.47 & 2.40 & 2.38 & 2.41 & 2.33 & 2.44 & 2.35 & 2.42 & 2.48 & 0.04 \\
$\mathrm{Sm}$ & 2.51 & 2.48 & 2.42 & 2.39 & 2.43 & 2.33 & 2.45 & 2.37 & 2.42 & 2.49 & 0.03 \\
$\mathrm{Eu}$ & 2.48 & 2.46 & 2.39 & 2.36 & 2.41 & 2.31 & 2.43 & 2.34 & 2.40 & 2.47 & 0.05 \\
$\mathrm{Gd}$ & 2.47 & 2.44 & 2.38 & 2.35 & 2.40 & 2.30 & 2.41 & 2.31 & 2.39 & 2.45 & 0.06 \\
$\mathrm{~Tb}$ & 2.43 & 2.41 & 2.34 & 2.33 & 2.36 & 2.28 & 2.39 & 2.29 & 2.36 & 2.42 & 0.08 \\
$\mathrm{Dy}$ & 2.44 & 2.41 & 2.33 & 2.32 & 2.35 & 2.28 & 2.38 & 2.29 & 2.36 & 2.42 & 0.09 \\
$\mathrm{Ho}$ & 2.43 & 2.40 & 2.32 & 2.32 & 2.35 & 2.28 & 2.40 & 2.29 & 2.34 & 2.42 & 0.10 \\
$\mathrm{Er}$ & 2.43 & 2.39 & 2.32 & 2.31 & 2.34 & 2.28 & 2.40 & 2.27 & 2.33 & 2.41 & 0.11 \\
$\mathrm{Tm}$ & 2.45 & 2.41 & 2.32 & 2.32 & 2.35 & 2.29 & 2.40 & 2.28 & 2.33 & 2.43 & 0.11 \\
$\mathrm{Yb}$ & 2.46 & 2.41 & 2.33 & 2.33 & 2.36 & 2.29 & 2.43 & 2.28 & 2.34 & 2.44 & 0.10 \\
$\mathrm{Lu}$ & 2.47 & 2.42 & 2.33 & 2.32 & 2.36 & 2.29 & 2.43 & 2.28 & 2.34 & 2.44 & 0.11 \\
\hline
\end{tabular}

*Unit is mmol/equiv. 
Appendix 4. $\log K_{M H A}\left(\right.$ Tipping, 1994) and $\log K_{M A}$ (Tipping, 1998) of HA for reference metal ions and logK (Martell et al., 2003) of reference ligands for metal ions

\begin{tabular}{|c|c|c|c|c|c|c|c|c|c|c|c|}
\hline & $\log K_{\mathrm{MHA}(\mathrm{HA})}$ & $\log K_{\mathrm{MA}(\mathrm{HA})}$ & $\log K_{\text {acetate(1:1) }}$ & $\log K_{\text {acetate(1:2) }}$ & $\log K_{\text {propionate }}$ & $\log K_{\text {citrate }}$ & $\log K_{\text {EDTA }}$ & $\log K_{\mathrm{NTA}}$ & $\log K_{\mathrm{IDA}}$ & $\log K_{\text {malonate }}$ & $\log K_{\text {lactate }}$ \\
\hline $\mathrm{Al}^{3+}$ & -1.3 & 2.6 & 2.75 & 4.6 & 2.3 & 9.98 & 19.0 & 13.3 & & 7.49 & 3.24 \\
\hline $\mathrm{Am}^{3+}$ & -1.2 & 2.5 & 2.8 & 4.62 & & 9.67 & 20.1 & 13.5 & 6.9 & & 3.04 \\
\hline $\mathrm{Ba}^{2+}$ & -3.6 & -0.2 & 1.07 & & 0.77 & 4.17 & 9.59 & 6.09 & 1.67 & 2.07 & 0.77 \\
\hline $\mathrm{Ca}^{2+}$ & -3.2 & 0.7 & 1.18 & & 0.93 & 4.87 & 12.4 & 7.74 & 2.6 & 2.5 & 1.48 \\
\hline $\mathrm{Cd}^{2+}$ & -2.7 & 1.3 & 1.92 & 2.72 & 1.6 & 4.98 & 18.1 & 11.0 & 5.71 & 3.45 & 1.7 \\
\hline $\mathrm{Cm}^{3+}$ & -2.0 & 2.2 & 2.87 & 4.42 & & 9.67 & 20.4 & 13.7 & & & \\
\hline $\mathrm{Co}^{2+}$ & -2.7 & 1.1 & 1.38 & 0.76 & 1.13 & 6.19 & 18.2 & 11.7 & 6.97 & 3.75 & 1.9 \\
\hline $\mathrm{Cu}^{2+}$ & -1.5 & 2.0 & 2.21 & 3.4 & 2.22 & 7.57 & 20.5 & 14.3 & 10.6 & 5.8 & 3.02 \\
\hline $\mathrm{Fe}^{3+}$ & -0.8 & 2.5 & 4.24 & 7.57 & 3.71 & 13.1 & 27.7 & 17.8 & & & \\
\hline $\mathrm{Mg}^{2+}$ & -3.3 & 0.7 & 1.26 & & 0.97 & 4.89 & 10.6 & 6.78 & 2.98 & 2.85 & 1.37 \\
\hline $\mathrm{Mn}^{2+}$ & -3.4 & 0.6 & 1.4 & & & 5.2 & 15.6 & 8.65 & 4.72 & 3.28 & 1.43 \\
\hline $\mathrm{Ni}^{2+}$ & -2.7 & 1.1 & 1.44 & 2.4 & 1.19 & 6.64 & 20.1 & 12.8 & & 4.1 & 2.2 \\
\hline $\mathrm{Pb}^{2+}$ & -1.7 & 2.0 & 2.58 & 4.02 & 2.64 & 5.67 & 19.7 & 12.8 & 7.36 & & 2.78 \\
\hline $\mathrm{Sr}^{2+}$ & -2.8 & 1.1 & 1.12 & & 0.86 & 4.43 & 10.4 & 6.27 & 2.23 & & 0.97 \\
\hline $\mathrm{Th}^{4+}$ & -0.6 & 2.8 & 4.69 & 8.18 & 4.76 & 14.2 & 26.7 & 15.0 & & & 5.03 \\
\hline $\mathrm{UO}_{2}{ }^{2+}$ & -1.3 & 2.2 & 3.11 & 5.04 & 2.94 & 8.69 & & 10.8 & 8.96 & & 3.13 \\
\hline $\mathrm{Zn}^{2+}$ & -2.3 & 1.5 & 1.57 & 1.91 & 1.44 & 6.06 & 18 & 11.8 & 7.15 & 3.84 & 2.22 \\
\hline $\mathrm{Y}$ & & & 2.32 & 4.24 & 2.53 & 9.42 & 20.64 & 13.34 & 6.78 & 5.69 & 3.64 \\
\hline $\mathrm{La}$ & & & 2.55 & 4.12 & 2.54 & 9.18 & 17.92 & 12.39 & 5.88 & 4.94 & 3.16 \\
\hline $\mathrm{Ce}$ & & & 2.60 & & & & 18.49 & 12.70 & 6.18 & & 3.21 \\
\hline $\operatorname{Pr}$ & & & 2.65 & 4.48 & 2.77 & 9.50 & 18.86 & 12.79 & 6.44 & 5.20 & 3.30 \\
\hline $\mathrm{Nd}$ & & & 2.67 & 4.54 & 2.85 & 9.51 & 19.07 & 13.02 & 6.50 & 5.24 & 3.37 \\
\hline $\mathrm{Sm}$ & & & 2.84 & 4.80 & 2.86 & 9.59 & 19.62 & 13.24 & 6.64 & 5.48 & 3.53 \\
\hline $\mathrm{Eu}$ & & & 2.77 & 4.71 & 2.88 & 9.46 & 19.81 & 13.24 & 6.73 & 5.58 & 3.55 \\
\hline $\mathrm{Gd}$ & & & 2.66 & 4.54 & 2.74 & 9.38 & 19.91 & 13.27 & 6.68 & 5.61 & 3.56 \\
\hline $\mathrm{Tb}$ & & & 2.55 & 4.30 & 2.65 & 9.30 & 20.43 & 13.42 & 6.78 & 5.73 & 3.60 \\
\hline Dy & & & 2.49 & 4.23 & 2.58 & 9.34 & 20.86 & 13.55 & 6.88 & 5.76 & 3.58 \\
\hline Но & & & 2.45 & 4.18 & 2.61 & 9.39 & 21.12 & 13.68 & 6.97 & 5.68 & 3.70 \\
\hline $\mathrm{Er}$ & & & 2.43 & 4.13 & 2.59 & 9.41 & 21.45 & 13.82 & 7.09 & 5.71 & 3.79 \\
\hline $\mathrm{Tm}$ & & & 2.47 & 4.09 & 2.56 & 9.55 & 21.88 & 13.99 & 7.22 & 5.71 & 3.82 \\
\hline $\mathrm{Yb}$ & & & 2.56 & 4.36 & 2.58 & 9.65 & 22.05 & 14.13 & 7.42 & 5.70 & 3.90 \\
\hline $\mathrm{Lu}$ & & & 2.49 & 4.23 & 2.65 & 9.67 & 22.30 & 14.24 & 7.61 & 5.74 & 3.95 \\
\hline
\end{tabular}


Appendix 5. $\log K_{M H A}$ of HA estimated by the LFER

\begin{tabular}{lccccccccc}
\hline & acetate (1:1) & acetate (1:2) & propionate & citrate & EDTA & NTA & IDA & malonate & lactate \\
\hline $\mathrm{La}$ & -1.73 & -1.74 & -1.75 & -1.69 & -2.24 & -1.95 & -2.42 & -2.20 & -1.59 \\
$\mathrm{Ce}$ & -1.68 & & & & -2.15 & -1.87 & -2.34 & & -1.55 \\
$\mathrm{Pr}$ & -1.63 & -1.63 & -1.57 & -1.60 & -2.09 & -1.85 & -2.27 & -2.09 & -1.47 \\
$\mathrm{Nd}$ & -1.61 & -1.61 & -1.51 & -1.60 & -2.06 & -1.79 & -2.26 & -2.07 & -1.42 \\
$\mathrm{Sm}$ & -1.43 & -1.53 & -1.51 & -1.58 & -1.97 & -1.74 & -2.22 & -1.96 & -1.29 \\
$\mathrm{Eu}$ & -1.50 & -1.56 & -1.49 & -1.61 & -1.94 & -1.74 & -2.20 & -1.91 & -1.27 \\
$\mathrm{Gd}$ & -1.62 & -1.61 & -1.60 & -1.64 & -1.93 & -1.73 & -2.21 & -1.90 & -1.27 \\
$\mathrm{~Tb}$ & -1.73 & -1.68 & -1.66 & -1.66 & -1.84 & -1.70 & -2.19 & -1.85 & -1.23 \\
$\mathrm{Dy}$ & -1.79 & -1.70 & -1.72 & -1.65 & -1.78 & -1.66 & -2.16 & -1.83 & -1.25 \\
$\mathrm{Ho}$ & -1.83 & -1.72 & -1.69 & -1.63 & -1.73 & -1.63 & -2.14 & -1.87 & -1.15 \\
$\mathrm{Er}$ & -1.85 & -1.74 & -1.71 & -1.63 & -1.68 & -1.60 & -2.11 & -1.85 & -1.08 \\
$\mathrm{Tm}$ & -1.81 & -1.75 & -1.73 & -1.59 & -1.61 & -1.56 & -2.08 & -1.85 & -1.06 \\
$\mathrm{Yb}$ & -1.72 & -1.66 & -1.72 & -1.56 & -1.59 & -1.52 & -2.03 & -1.86 & -0.995 \\
$\mathrm{Lu}$ & -1.79 & -1.70 & -1.66 & -1.55 & -1.55 & -1.50 & -1.98 & -1.84 & -0.955 \\
$\mathrm{Y}$ & -1.96 & -1.70 & -1.75 & -1.62 & -1.81 & -1.72 & -2.19 & -1.86 & -1.20 \\
\hline
\end{tabular}

Appendix 6. $\log K_{M A}$ of HA estimated by the LFER

\begin{tabular}{lccccccccc}
\hline & acetate $(1: 1)$ & acetate $(1: 2)$ & propionate & citrate & EDTA & NTA & IDA & malonate & lactate \\
\hline $\mathrm{La}$ & 1.78 & 1.98 & 1.89 & 2.00 & 1.53 & 1.78 & 1.34 & 1.60 & 2.08 \\
$\mathrm{Ce}$ & 1.81 & & & & 1.61 & 1.85 & 1.41 & & 2.12 \\
$\mathrm{Pr}$ & 1.84 & 2.07 & 2.03 & 2.07 & 1.66 & 1.87 & 1.47 & 1.72 & 2.18 \\
$\mathrm{Nd}$ & 1.86 & 2.08 & 2.08 & 2.07 & 1.69 & 1.92 & 1.48 & 1.74 & 2.23 \\
$\mathrm{Sm}$ & 1.97 & 2.14 & 2.09 & 2.06 & 1.79 & 1.96 & 1.51 & 1.85 & 2.34 \\
$\mathrm{Eu}$ & 1.93 & 2.12 & 2.10 & 2.04 & 1.80 & 1.97 & 1.53 & 1.89 & 2.36 \\
$\mathrm{Gd}$ & 1.85 & 2.08 & 2.01 & 2.02 & 1.88 & 2.00 & 1.52 & 1.91 & 2.36 \\
$\mathrm{~Tb}$ & 1.78 & 2.02 & 1.96 & 2.03 & 1.93 & 2.03 & 1.55 & 1.96 & 2.39 \\
$\mathrm{Dy}$ & 1.73 & 2.01 & 1.91 & 2.05 & 1.97 & 2.06 & 1.57 & 1.97 & 2.38 \\
$\mathrm{Ho}$ & 1.71 & 1.99 & 1.93 & 2.05 & 2.02 & 2.09 & 1.59 & 1.94 & 2.46 \\
$\mathrm{Er}$ & 1.69 & 1.98 & 1.92 & 2.08 & 2.07 & 2.13 & 1.62 & 1.95 & 2.52 \\
$\mathrm{Tm}$ & 1.72 & 1.97 & 1.90 & 2.11 & 2.10 & 2.16 & 1.64 & 1.95 & 2.54 \\
$\mathrm{Yb}$ & 1.78 & 2.04 & 1.91 & 2.11 & 2.13 & 2.18 & 1.69 & 1.95 & 2.60 \\
$\mathrm{Lu}$ & 1.73 & 2.01 & 1.96 & 2.05 & 1.90 & 1.99 & 1.73 & 1.97 & 2.64 \\
$\mathrm{Y}$ & 1.62 & 2.01 & 1.88 & 2.00 & 1.53 & 1.78 & 1.55 & 1.94 & 2.42 \\
\hline
\end{tabular}



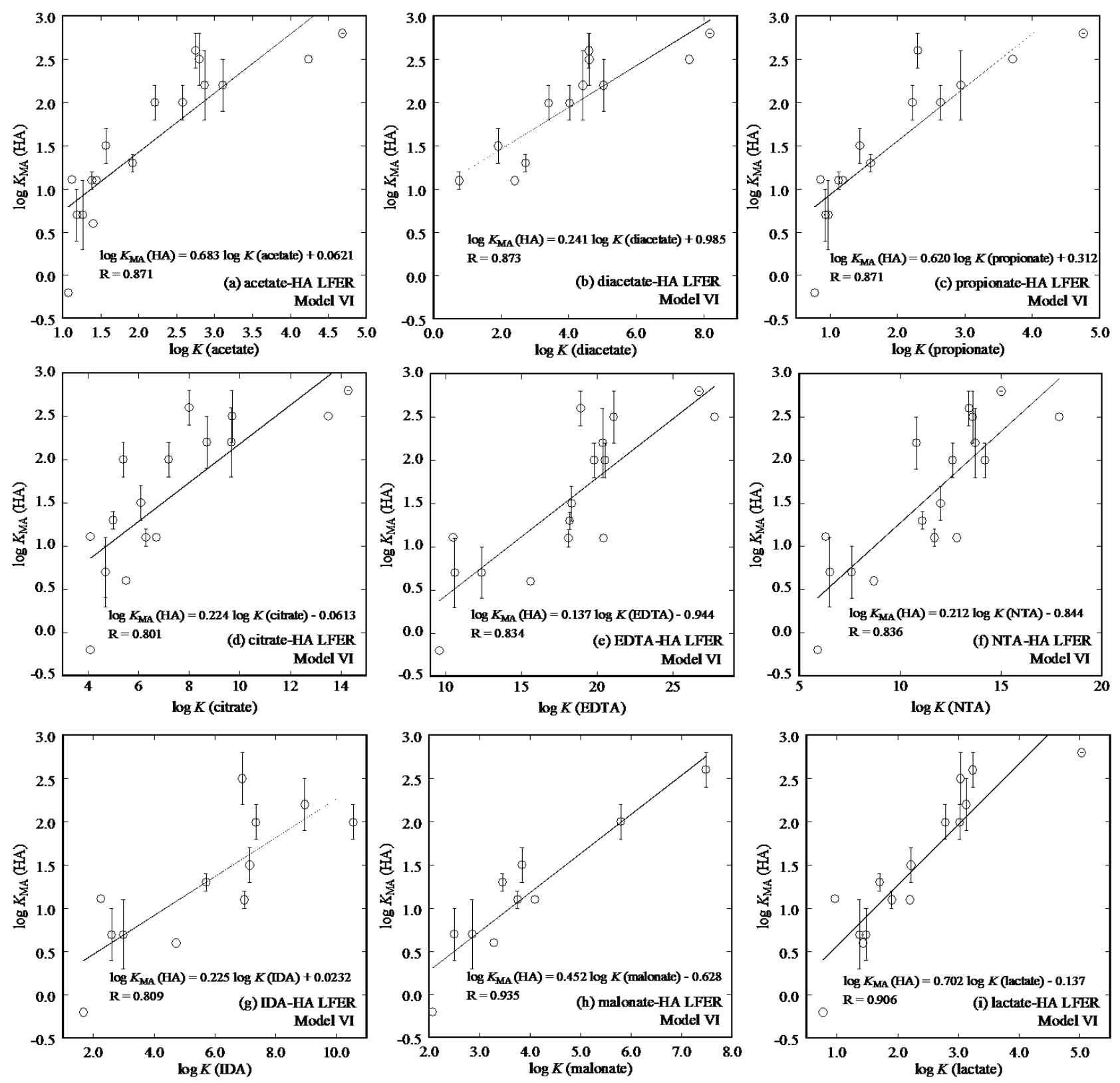

Appendix 7. Linear free energy relationship (LFER) between $\log K_{M A}$ for $H A$ and the stability constants for carboxylates 

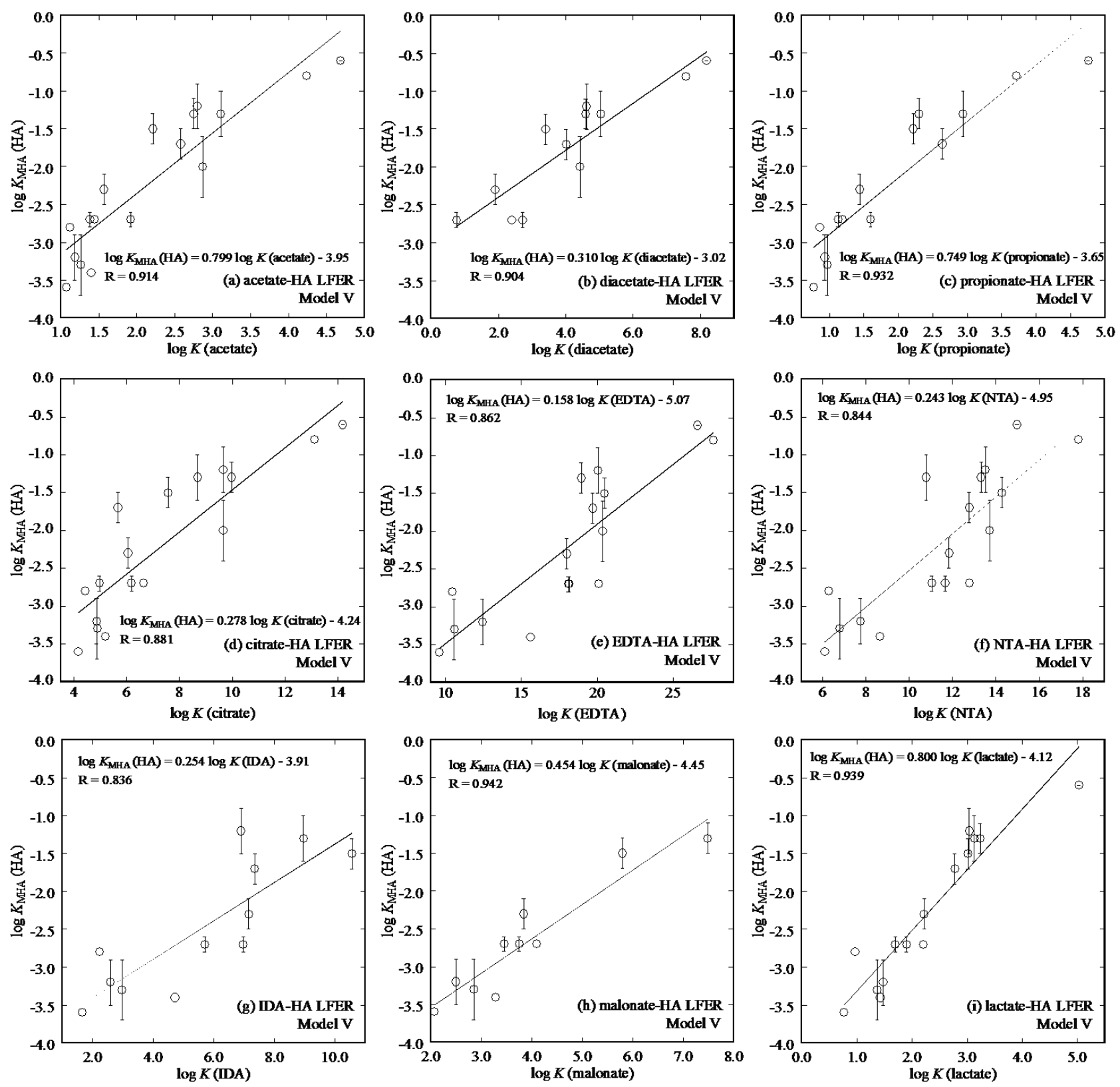

Appendix 8. Linear free energy relationship (LFER) between $\log K_{M H A}$ for HA and the stability constants for carboxylates 